\title{
Measuring the Importance of Political Elites*
}

\author{
Simon Munzert (Hertie School of Governance) ${ }^{\dagger}$
}

This version: December 14, 2018

Abstract. Political influence and prominence are both important drivers and outcomes of political careers, however are hard to quantify. I develop a method to measure these characteristics for a large set of political elites using information from the largest database of politicians-the English Wikipedia. I argue that metadata from the encyclopaedia, such as article editing, readership metrics, and linkage structures are reflective of the latent traits. A Bayesian latent variable model is employed to identify prominence and influence scores for a set of 45,000 U.S. politicians. Several validation exercises corroborate the superiority of the measures over existing alternatives. To illustrate their usefulness, I present an analysis of media appearances of political elites. The ability to measure the importance of political elites on a large scale has various implications for the understanding of political career paths, electoral performance, and legislative politics.

Word count. 9,980

\footnotetext{
${ }^{*}$ I am grateful to Sascha Göbel and Angela Peckham for superb research assistance. I thank Andrew Guess, Julian Wucherpfennig, Mark Kayser, Peter Selb, and Sascha Göbel for valuable comments on a previous version of the manuscript. Also, many thanks for helpful feedback go to participants of the workshop Citizen and Elite Activity on Wikipedia held at Hertie in December 2017. Previous versions of the paper were presented at the 2017 APSA annual meeting in San Francisco and the 2018 EPSA annual meeting in Vienna.

${ }^{\dagger}$ Lecturer in Political Data Science, Hertie School of Governance. Address: Friedrichstrasse 180, 10117 Berlin, Germany. Email: munzert@hertie-school.org, Web: https://simonmunzert.github.io.
} 
"The love of fame [is] the ruling passion of the noblest minds."

-Alexander Hamilton (The Federalist 72, 1788)

\section{Introduction}

In representative democracies, political elites play a key role in setting the political agenda. Knowledge about representatives in major legislative and executive branches of government is crucial for a deeper understanding of politics and policy-making processes. Therefore, multiple strands of research focus on elite behavior and preferences, seeking to describe ideological positions (e.g., Bonica, 2013; Poole and Rosenthal, 1985), alignment with constituents (e.g., Clinton, 2006), personality traits (e.g., Ramey, Klingler and Hollibaugh Jr., 2016), and career paths (e.g., Norris, 1997; Ohmura et al., 2017), among others. By modern standards, the focus on individual political elites in the study of politics seems all the more warranted, as campaigns increasingly focus on candidates instead of programs (Holtz-Bacha, Langer and Merkle, 2014) and with personalization in politics in general on the rise (Garzia, 2011; Rahat and Sheafer, 2007).

However, politicians differ vastly in their influence over decision-making processes, but also in their perceived prominence by the public. Surprisingly, there is currently no established method to quantify political importance for a given set of political actors. Existing proxies, such as seniority or incumbency status, are often employed ad hoc and without a theoretical foundation. This gap is astounding, since fame and influence-to both of which political power is instrumental-are often considered to be among the main motivators of political careers (e.g., Fong, Malhotra and Margalit, 2017; Murphy and Stuckey, 2002).

To address this blind spot in our understanding of political elites, I propose a compound measure that captures two core dimensions of importance: prominence, which reflects the contemporary (and at times short-lived) attention a politician receives, and political influence, a relational feature that captures the size of the politician's footprint left in the political arena through her political activity.

The measurement approach exclusively rests on data from the online encyclopedia Wikipedia. The platform provides data as by-products of their original raison d'être that hap- 
pen to reflect the importance of its featured entities in multiple ways. In particular, more important politicians receive more extensive attention-both by editors and readers-and are more deeply linked in the Wikipedia graph of knowledge.

To demonstrate the value of the measure, I apply it to a set of 45,004 U.S. politicians who, as of January 2018, were featured on the English Wikipedia. I then present a set of validation exercises using alternative importance measures as benchmarks. They both corroborate the validity of the measure and illustrate its superiority over alternative indicators. Finally, I present an application to illustrate the usefulness of the measure in tracking the role of political importance for coverage of political elites in the media.

The suggested measurement approach features a number of desirable characteristics: First, it is largely independent of context-specific institutional features. Using this approach, researchers are not burdened with manually defining importance attached to particular offices or levels of seniority. Second, it allows distinguishing between both the political influence that emerges from a politician's career and the political prominence that is primarily defined by public awareness. Third, it is applicable to various sets of elites who are positioned in different contexts across space and time.

\section{Dissecting Political Importance}

The idea to quantify the importance of outstanding humans is not new. However, what makes a person politically important? This paper quantifies political importance by distinguishing between components which contribute to a politician's importance with standards of popular perception on the one hand, and with actual political influence on the other.

Some of the characteristics that shape politician's placement within these dimensions are manifest, such as high-profile offices, seniority, incumbency status, or name-recognition in the public. Other features are latent, such as reputation among peers, agendasetting power, and personality traits such as charisma, valence, and responsiveness. It is largely unclear, however, under which conditions and to what extent these characteristics reflect the concept of interest, which renders it difficult to use them as proxies of political 
importance. Being re-elected multiple times, for instance, might increase name recognition among constituents, but does not necessarily imply political influence in terms of legislation influenced or reputation gained among peers. Equally, someone's fame in the public does not necessarily translate to their level of influence in the political sphere.

A person's political importance, as introduced here, is therefore a combination of her prominence, which is manifest and latent characteristics that reflect her perceived current importance and "worthiness of attention", and her political influence, which comprises her ability to shape the political agenda as well as actual political output. For contemporary politicians, this is strongly related to political power (Ban et al., 2018; Fouirnaies and Hall, 2015); for historical figures it is linked to political achievements (Murray and Blessing, 1988).

Prominence and political influence are not necessarily orthogonal to each other. Outstanding political offices such as senatorship or presidency grant officeholders a massive boost in celebrity status as well as the power to influence political outcomes. Prominence and influence also might mutually reinforce each other. Name recognition has been considered an important determinant of electoral success (Abramowitz, 1988; Kam and Zechmeister, 2013), implying that prominence can serve as a mode of access to political influence. By the same coin, achievements in political office potentially raise public awareness for the individual.

The idea of political importance speaks to various other related concepts. The literature on candidate valence argues that non-policy factors such as character traits, attractiveness, or incumbency status can lead voters to support candidates who do not represent the closest match based on the policy profile alone (e.g., Andersen and Kibler, 1978; Buttice and Stone, 2012). While the research in this area is vast, there is no consensus on a comprehensive measure of valence (Nyhuis, 2016). Some argue that it comprises features of candidate quality, including "characteristics, abilities, and traits such as integrity and skills in governing that voters value intrinsically in their elected officeholders" (Buttice and Stone, 2012, 871), while others have emphasized manifest criteria such as incumbency status or access to significant campaign resources (Jacobson and Kernell, 1983). Moreover, research on valence primarily highlights the importance of personal, quality- 
based characteristics for the evaluation of electoral success, but tells little about long-term achievements in terms of popular perception or political influence.

Existing practice also has limitations of measurement. As a standard procedure, a set of manifest indicators, such as incumbency status, tenure, and public or party office (or a subset thereof) is plugged into models of legislative behavior to proxy latent influence, seniority, or quality of representatives (see, e.g., Hall and Shepsle, 2013; Hitt, Volden and Wiseman, 2017, for recent variants of this practice). While these indicators may be fairly straightforward to collect for a well-defined set of political actors, they will often be less than optimal accounts of the actual trait of interest. For instance, seniority in the United States Senate is a common way to distinguish between a"senior senator" and a "junior senator" representing a particular state, and is primarily defined by tenure. This has real-life implications, as senior senators are formally granted more power. Time in office, however, is not necessarily informative of a senator's influence, achievements, or prominence. Furthermore, indicators based on occupation of office make it generally difficult to compare politicians across political institutions (such as state and federal legislators). To combat the limitations of manifest indicators, several indirect importance measures have been suggested. In a recent contribution, Ban et al. (2018) introduce an innovative newspaperbased measure of political power. In particular, they expect coverage to reflect "whether, and to what extent, various political actors and offices possess the necessary resources and authority to influence political outcomes, that is, to "matter" for the political process" (Ban et al., 2018, 3). While this definition of power is similar to the concept of political influence that is followed here, the operational nature rather corresponds to prominence: The authors themselves note that "[c]elebrities, for example, may not be politically powerful but will often be featured in the news" (Ban et al., 2018, 2). Moreover, media presence might not only be reflective of actual prominence but also of politicians who see the power of media as instrumental to their strategic goals (Cohen, Tsfati and Sheafer, 2008).

In other recent work, Fouirnaies and Hall (2015) as well as Ban, Moskowitz and Snyder (2016) use campaign contributions as a proxy for power, arguing that potential donors give strategically to gain access (Kalla and Broockman, 2016; Snyder, 1992). While such a measure is particularly appealing from a theoretical perspective, it is somewhat limited 
to the U.S. system and campaign periods. Moreover, such a measure might speak more to expected power (e.g., via committee memberships) in policy areas with well-funded interest groups than to more general political influence.

\section{A Measure of Political Importance Using Wikipedia Data}

\section{Wikipedia as a database}

To arrive at a widely applicable yet flexible measure of political importance, I suggest to draw on the presumably largest database of politicians worldwide: the online encyclopaedia Wikipedia. Over the years, Wikipedia has grown to be a significant and trusted source of information that has outpaced traditional encyclopaedias in terms of reach, coverage, and comprehensiveness (Giles, 2005). It is regularly listed among the most-visited website worldwide. At the advantage of the suggested measurement approach, this platform features biographical entries of tens of thousands of politicians, often with an astonishing level of detail. In addition to the content of the platform itself, much of metadata on the use of the platform by editors and readers is made publicly available by the Wikimedia Foundation. In the following, I argue that through the processes that generate these data, they are indicative of both the contemporary prominence and the political influence of politicians featured on the platform.

\section{Quantifying prominence}

Prominence, as defined here, refers to the attention paid to individuals by the public. Public attention, in turn, can be seen as the scarce resources people are willing to invest in thinking about an issue or person (Ripberger, 2011). Metadata on Wikipedia usage provides a manifestation of this investment. I capitalize on the driving force of knowledge production on the platform, being that everyone is able to contribute to the project by adding, modifying, or removing content. It has been shown that the editor's interest in the topic serves as a strong predictor of editing activity (Lieberman and Lin, 2009). Consequently, articles on popular topics offer information in greater detail, are revised more 
often by a larger pool of editors, and experience more visits by ordinary users. Politicians' entries are no different. Even in a sample of articles on high-profile political elites, such as the Members of Congress, there is large variation in attention, with top-ranking politicians receiving thousands of daily page views on average and rank-and-file members getting no more than a few dozen.

In addition to baseline differences, offline events which attract collective attention are also reflected in bursting editing activity and readership of associated articles (GarcíaGavilanes, Tsvetkova and Yasseri, 2016). Naturally, this also applies to political figures covered in the encyclopaedia. Events triggering such bursts include anything that is newsworthy, such as scandals, special elections, or controversial statements. I argue that these patterns do not add as noise to the measure of prominence, but reflect its short-term nature.

To capture all these dynamics, I consider a set of indicators of editing activity and readership that are available via Wikimedia's APIs. In particular, I measure the article size in characters, the total number of unique editors of an article, the total number of revisions (additions, deletions, reverts), and the number of page views (i.e. how often an entry has been accessed on a given day) for any article in any given time span, provided that the article existed at that point.

\section{Quantifying influence}

Attention to a politician's Wikipedia page is not necessarily indicative of a figure's political importance in terms of influence. Many articles are popular, so inferring influence from the popularity of a politician's entry falls short in accuracy. To capture this dimension, I draw on the valuable feature that content is heavily linked on the platform. Links between articles are primarily manually defined by human editors contributing to the project. These links are not set randomly but are supposed to indicate a meaningful relationship between entities or articles (Wikipedia Manual of Style, 2017). The link structure has been exploited earlier to derive measures of centrality for all nodes (articles) in the network (see, e.g., Eom and Shepelyansky, 2013; Skiena and Ward, 2013). 
The underlying intuition is that more important pages have more incoming links (i.e. other pages referring to this page) than less important pages. How does this speak to the concept of political importance? As discussed earlier, political influence should manifest in a vast number of real-world outcomes, such as the record in law-making or holding high-ranking political offices. However, politics is a social business: Legislative influence requires regular collaboration with peers (Bratton and Rouse, 2011; Fowler, 2006), party networks provide access to resources and power (Cohen et al., 2009; Norris, 1997), and politicians are immediately linked to each other through their positions, constituencies, and actions. The linkage structure provided by a network of Wikipedia articles on politicians certainly does not provide a comprehensive real-world representation of the formal and informal networks. However, I argue that the centrality of actors within this network is already revealing about relative political influence.

In order to make sense of the linkage structure, I follow an established practice and implement the PageRank algorithm, which has originally been developed to rank webpages by Google search engine importance (Brin and Page, 1998). Section C in the Online Appendix (p. 9) provides a more detailed discussion of the application of PageRank to political elites on Wikipedia. I will consider two versions of the PageRank algorithm-the first takes the network of politicians as a basis, the second includes all other articles that are featured on the Wikipedia, as one could argue that the importance of a person is not (only) defined by the importance of peers, but also by her position and role in the political system, ties to legislative output, or events.

\section{Data and Estimation}

\section{Data collection}

I collected data on observations that were classified as politicians with U.S. citizenship on Wikidata, a free and collaboratively edited online knowledge base for data of all kind (Vrandečić and Krötzsch, 2014). I removed observations that did not have an entry on the En- 
glish Wikipedia or were either erroneously classified. This effort, which reflects a snapshot of the platform as of January 26, 2018, resulted in 45,004 observations.

I then collected various metadata associated with the politicians' Wikipedia entries. To that end, I queried the XTools Page API at xtools.wmflabs.org, which provides information on the number of revisions (additions, deletions, and reverts), editors, and article size. Furthermore, I accessed the Wikimedia Traffic API to download daily page views statistics for all entries. Finally, I downloaded all articles and identified cross-links to construct a directed graph. This was then used to compute the PageRank for each article within the network of politicians. To retrieve the global PageRank (computed on the entire graph of English Wikipedia articles) I matched data provided by Thalhammer (2017). Entries with data missing for one of these variables were excluded. Due to few but massive outliers, the distributions of all variables are heavily right-skewed. I use logged variables in all following analyses. Summary statistics of the raw and logged variables are provided in Tables B1 and B2 as well as in Figure B2 in the Online Appendix (p. 3).

\section{Statistical model and estimation}

While I expect some indicators to reflect latent political influence (in particular the PageRank indicators) and others to mirror prominence (in particular editing activity and page views), it is unclear a priori whether the data can be largely described by two dimensions, to what extent they are separable, and what the individual indicators contribute to the latent dimensions of importance.

I start by investigating the dimensionality of the data. A scree test indicates that two factors seem sufficient to describe dimensionality of the underlying correlations (see Figure $\mathrm{B}_{3}$ in the Online Appendix, p. 5). This is consistent with my conceptualization of political importance as a combination of prominence and influence. Parallel analysis suggests a similar solution. I therefore extract two dimensions from the data matrix.

Having established that there is a low-dimensional underlying structure in the data, I specify a Bayesian latent variable model to identify latent dimensions of importance and to derive scores that can be used in subsequent models. The procedure largely follows 
Merkle and Wang (2016). Assume a set of $n$ politicians for which one observes values on $p$ indicators, giving $y_{i j}(i=1, \ldots, n ; j=1, \ldots, p)$, which is individual $i$ 's value on observed indicator $j$. Now, assuming that $m=2$ latent factors impact the observed outcomes, the following model is specified:

$$
\begin{gathered}
y_{i j} \mid \boldsymbol{\theta}_{i}, \gamma_{j}, \boldsymbol{\Lambda}_{j}, \psi_{j} \sim N\left(\mu_{i j}, \psi_{j}\right) \text { for all } i, j \\
\mu_{i j}=\gamma_{j}+\sum_{k=1}^{2} \lambda_{j k} \theta_{i k} \\
\boldsymbol{\theta}_{i} \sim N_{m}(\mathbf{0}, \boldsymbol{\Phi}) .
\end{gathered}
$$

The observed outcome $y_{i j}$ is a function of the intercept $\gamma_{j}$ (indicator $j$ 's population mean), the factor loadings $\lambda_{j k}$, which reflect the extent to which observed values on the indicator $j$ are determined by the latent factors, $\theta_{i k}$, the individual $i$ 's position on the respective latent factor (the factor score), and a random noise with variance $\psi_{j} . \boldsymbol{\theta}_{i}$ is a vector of factor scores that arises from a multivariate normal distribution, where matrix $\Phi$ represents the variance of each latent trait in the population along with the covariances between pairs of traits. $\Lambda_{j}$ holds the factor loadings of indicator $j$.

The model specified in the previous equations is not identified. To address this issue, I adopt a parameter expansion approach (Gelman, 2004; Merkle and Wang, 2016). Essentially, this involves sampling from a model with unidentified parameters and, at each iteration, transforming the sampled parameters into identified ones. After fixing one parameter each in $\Lambda_{j}$ to zero, the following prior distributions are used for the rest of the (unidentified, as indicated by the asterisks) parameters:

$$
\begin{gathered}
\lambda_{j k}^{*} \sim N(0,1) \text { for unconstrained } \lambda_{j k}^{*} \\
\boldsymbol{\theta}_{i}^{*} \sim N_{m}(\mathbf{0}, \boldsymbol{\Phi}) \text { for } i=1, \ldots, n \\
\boldsymbol{\Phi}^{*-1} \sim \operatorname{Wishart}(\boldsymbol{V}, 2),
\end{gathered}
$$

with $\boldsymbol{V}$ being a $2 \times 2$ covariance matrix that is left unconstrained. At each MCMC iteration, the parameters are then transformed into identified versions via 


$$
\begin{gathered}
\lambda_{j k}=\operatorname{sign}\left(\lambda_{k k}^{*}\right) \lambda_{j k}^{*} \Phi_{k k}^{* 1 / 2} \\
\theta_{i k}=\operatorname{sign}\left(\lambda_{k k}^{*}\right) \Phi_{k k}^{*-1 / 2} \theta_{i k}^{*} \\
\phi_{k l}=\frac{\operatorname{sign}\left(\lambda_{k k}^{*}\right) \operatorname{sign}\left(\lambda_{l l}^{*}\right) \phi_{k l}^{*}}{\sqrt{\phi_{k k}^{*} \phi_{l l}^{*}}}, k, l=1,2,
\end{gathered}
$$

where $\operatorname{sign}\left(\lambda_{k k}^{*}\right)$ is 1 if $\operatorname{sign}\left(\lambda_{k k}^{*}\right)$ is positive and -1 if $\operatorname{sign}\left(\lambda_{k k}^{*}\right)$ is negative. These transformations restrict the variances in $\Phi$ to equal 1. The covariances remain unconstrained, allowing the latent factors to be correlated. This is consistent with my previous reasoning that the underlying dimensions are likely not independent of each other. Prior distributions on the remaining model parameters are taken to be uninformative, with $\psi_{j} \sim$ $\operatorname{Inv-Gamma}(0.1,0.1)$ and $\gamma_{j} \sim N\left(0,10^{3}\right)$.

I implement the model in JAGS (Plummer, 2003) and R (R Core Team, 2017) to make inference about the parameters. Using three chains, a burn-in period of 2,500 iterations, and a posterior sample of 500 draws each, a satisfying model convergence based on timeseries plots and the Gelman-Rubin statistic is achieved. ${ }^{1}$

\section{Results}

Figure 1 reports the loadings ( $\hat{\lambda}_{j k}$ 's) of the variables on two factors, which I label "prominence" and "influence", just as the two presumed dimensions of political importance. ${ }^{2}$ The indicators are separated into two fairly distinct subsets. While an individual's prominence is strongly related to the amount of revisions and editors as well as the size of her article (all with loadings greater than o.6), influence mainly reflects in both PageRank indicators and the number of language editions covering this person (loadings between 0.57 and 0.60). The page views variable loads fairly strong ( 0.66 and 0.69 ) on both dimensions. While the indicator is of limited help to discriminate between the two dimensions, the variable is retained, as it still provides valuable information to separate cases that score high on both dimensions from those that score low. Both factors are highly positively cor-

\footnotetext{
${ }^{1}$ The JAGS code used to implement the model is reported in Online Appendix A, p. 2.

${ }^{2}$ The numeric results of the model are reported in Table B3 in the Online Appendix, p. 3.
} 
Figure 1: Estimated factor loadings from Bayesian latent variable model with $m=2$ factors.
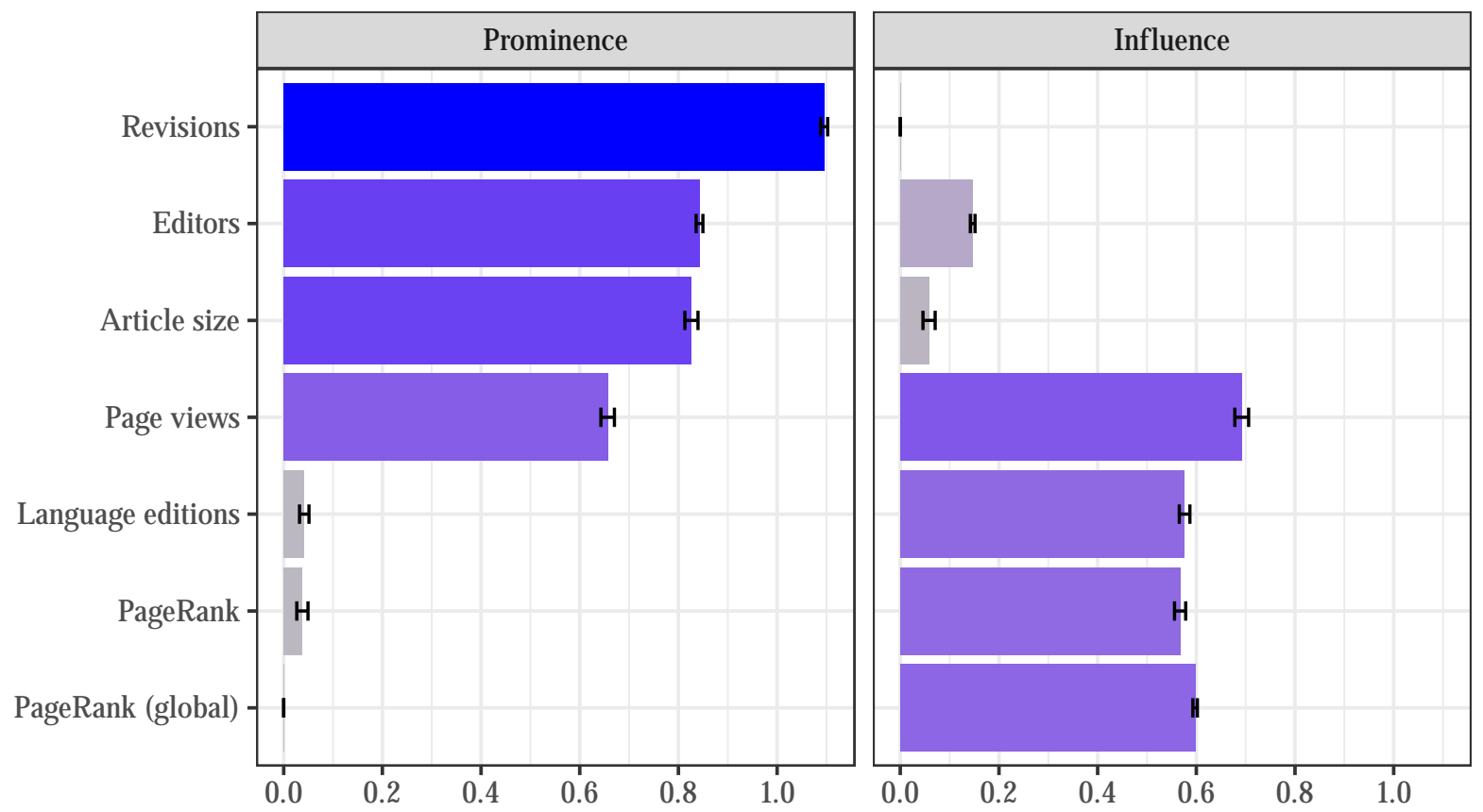

Note: Loadings for PageRank (global) and Revisions have been fixed on o for one of the two factors each, an identification constraint implemented in the exploratory model that makes further rotation unnecessary. Color intensity of the bars reflects the magnitude of the loading. Whiskers provide $95 \%$ credible intervals around the median.

related $\left(\hat{\phi}_{12}=.80\right)$, affirming the conjecture that the two dimensions should not be treated as independent of each other.

Next, I study the individual standings on the extracted dimensions, given by $\hat{\theta}_{i k}$. Figure 2 presents the latent variable values for all 45,004 individuals in the sample. The results mirror the strong correlation between both factors, whereas there is some variation in the ratio of in-sample influence rank vs. prominence rank, as highlighted by the colors. The vast majority of politicians is located in a space of very low levels of influence and prominence in the lower-left corner (partially obscured by the overplotting, but note that both variables have fixed means of $o$ and variances of 1 ). The influence distribution is also much more positively skewed (skew $=2.64$ ) than the prominence distribution $(0.85)$, which is also due to the fact that many biographies do not have a single incoming link from other biographies and are not featured in editions other than the English Wikipedia. Lack- 
Figure 2: Estimated person values from the Bayesian latent variable model.

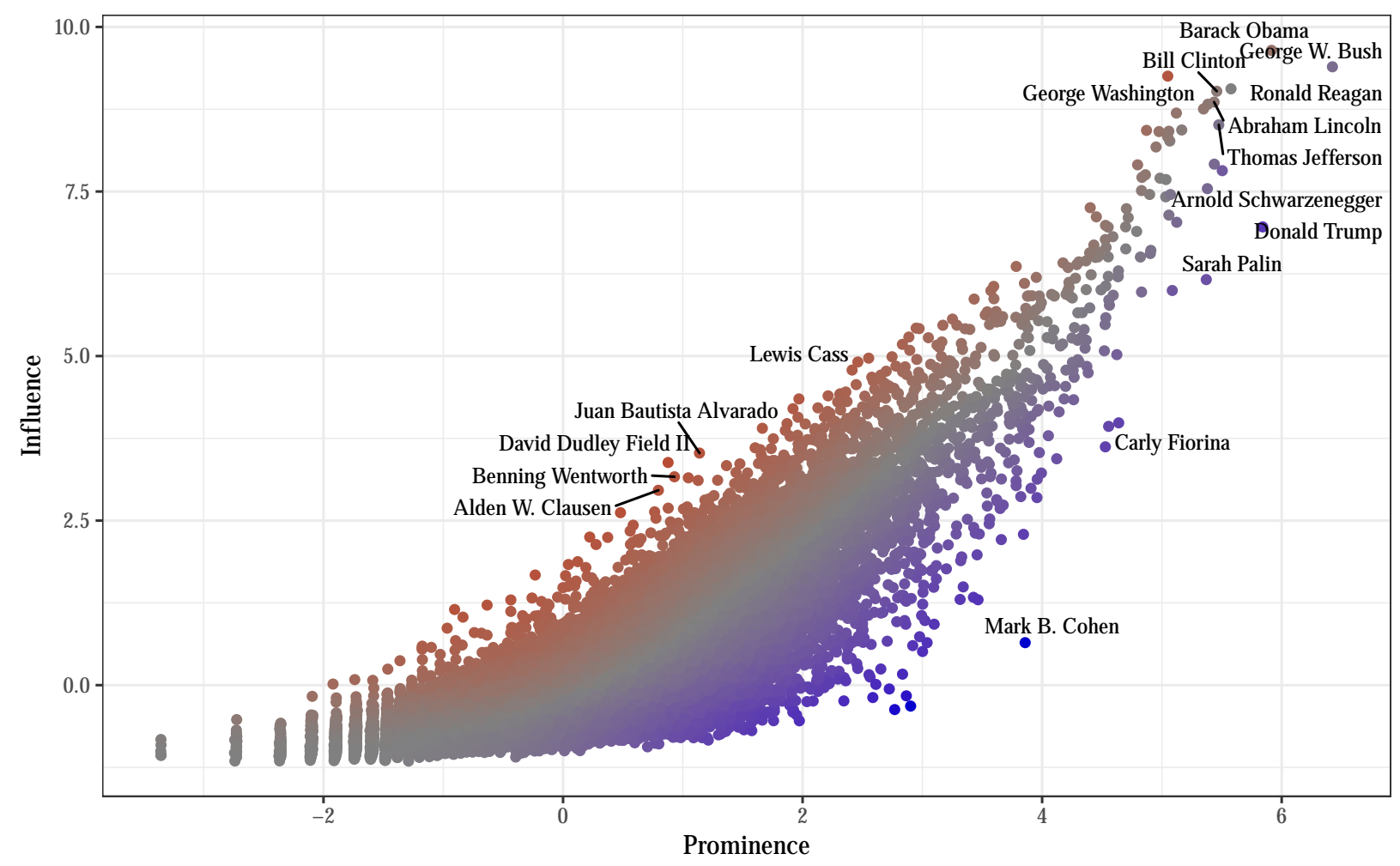

Note: Individual points indicate the medians of the estimated latent variable values on two dimensions. The colors indicate an individual's relative standing on both variables-red indicates that an individual ranks higher on influence than on prominence in the sample, blue indicates the opposite.

ing any credible benchmark data, it is difficult to judge the validity of the measures in this area of the latent space. The labeled observations in the high-rank as well as the borderline areas provide some face-validity: In the upper-right corner is a cluster of former U.S. presidents who score high on both dimensions, with the two most recent presidents, Barack Obama and George W. Bush, dominating the rankings. Donald Trump is among the most prominent politicians but ranks substantively lower on influence. He shares this characteristic with other individuals such as Sarah Palin or Carly Fiorina, who have achieved nation-wide fame but had limited influence on the political agenda. The plot also points to several interesting cases at the other margin, such as Lewis Cass, a 19th century politician who held various high-level political offices and ultimately ran unsuccessfully for the presidency in 1848 as the Democratic Candidate. It seems plausible that historical com- 
pared to contemporary figures, as well as those who were important politicians but never reached the highest offices, are located in this latent variable space.

\section{Robustness}

Skeptics may argue that both the factor solution and the derived scores on the two dimensions could be significantly shaped by single variables in the variable set or the sample choice. To address these concerns, I re-estimated the factor model multiple times, each time dropping one of the indicators. The results for the estimated factor loadings are reported in Figure B5 in the Online Appendix (p. 8). The results appear very similar to the full model, with the exception of the specification with the global PageRank variable dropped-here, the language editions variable has substantively more weight on the influence dimension. In the next step, I correlate the individual scores on both dimensions of the full model with those of the reduced models (see Table B4 in the Online Appendix, p. 4). The scores are almost perfectly correlated (correlations between $r=0.991$ and 1), again with the only exception of the correlation between the influence scores of the full model and those from the model with the global PageRank variable dropped $(r=0.907)$.

In addition, I re-estimated the model while restricting the data to certain characteristics, including subsamples of high-profile (in-sample prominence rank $\leq 1,000$ ) versus lowprofile politicians (prominence rank $\geq 30,000$ ), members of Congress, and alive members of Congress. Again, the individual scores are almost perfectly correlated with the original scores (correlations between $r=0.981$ and 1 ). The exception is the sample of low-profile politicians, where the correlation drops to $r=0.903$ for the prominence and $r=0.809$ for the influence scores. This should be of little relevance for most practical applications. These exercise indicates that the measures are neither primarily driven by one of the variables nor by the sample choice. It also shows that the individual values are remarkably robust towards a reduction of the variable set or set of politicians. 


\section{Validation}

I now present a set of evaluations to trial the validity of the measures. I start with a comparison of a high-profile subset of politicians-the U.S. presidents-by utilizing pollbased measures of political achievement. Next, I use original ranking data collected on the crowd-sourcing platform Amazon MTurk to provide more internally valid benchmarks. Third, I compare the measure with commonly used leadership and seniority indicators. Lacking an established measure of political importance, it is difficult to assess convergent validity, and it can be argued that all alternative measures used in this section capture related but not identical traits. It will be left to more than just one application of the measure, which I present below, to study substantive questions of political behavior and therefore judge its practical usefulness.

\section{Rankings of U.S. presidents}

In a first effort, I compare the estimated scores with a compiled list of rankings of presidential greatness. ${ }^{3}$ These historical rankings have a long tradition and are built on surveys among scholars (e.g., Schlesinger, 1962; Schlesinger Jr., 1997) or the general public (e.g., Cohen, 2003). They are certainly not an optimal benchmark: Scholars have used them to measure "presidential greatness", i.e. the legacy of a presidency in general as well as individual leadership qualities or failures. This is not identical with either prominence or influence. Bad performance in office does not necessarily imply limited prominence or even influence. ${ }^{4}$ Bearing these limitations in mind, it is of interest to see how these measures relate to each other.

I now compare the Wikipedia-based rankings to those from scholarly expert rankings. To that end, I use data from 18 surveys that have been conducted between 1948 and 2017 and compute the average rank for all presidents across all surveys with non-missing values (see Table B7 in the Online Appendix, p. 6, for an overview of all sources and associated

${ }^{3}$ See Figure B4 in the Online Appendix (p. 7) for the distributions of the estimated ranks within the sample of presidents across all simulations.

${ }^{4}$ For instance, while Andrew Johnson is widely regarded as one of the worst presidents in U.S. history, people and scholars are still historically aware of the significance of the period he held office. 
Figure 3: Influence ranks of U.S. presidents versus ranks from scholarly expert surveys.

(a) Raw measure

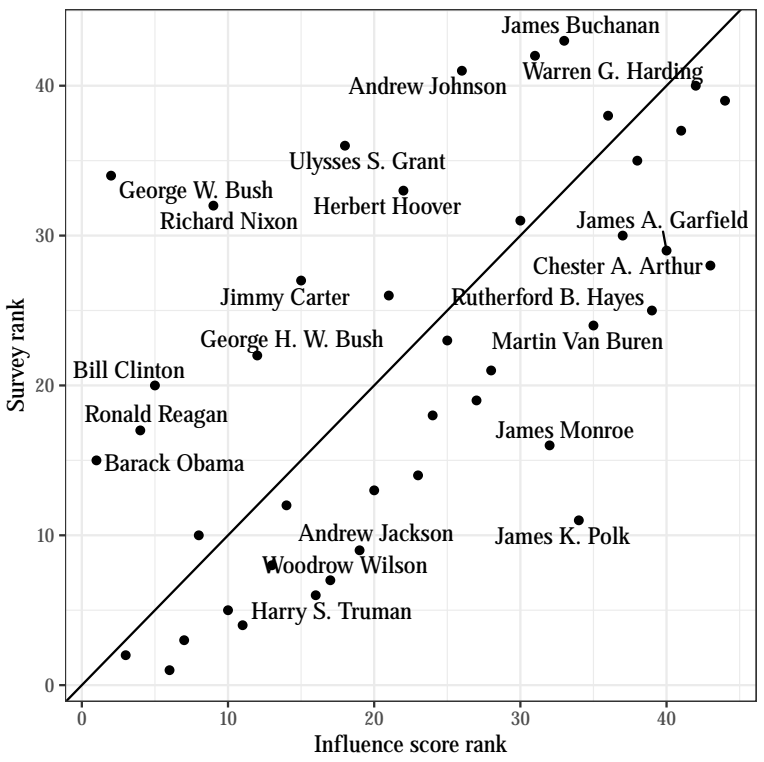

(b) Time de-biased measure

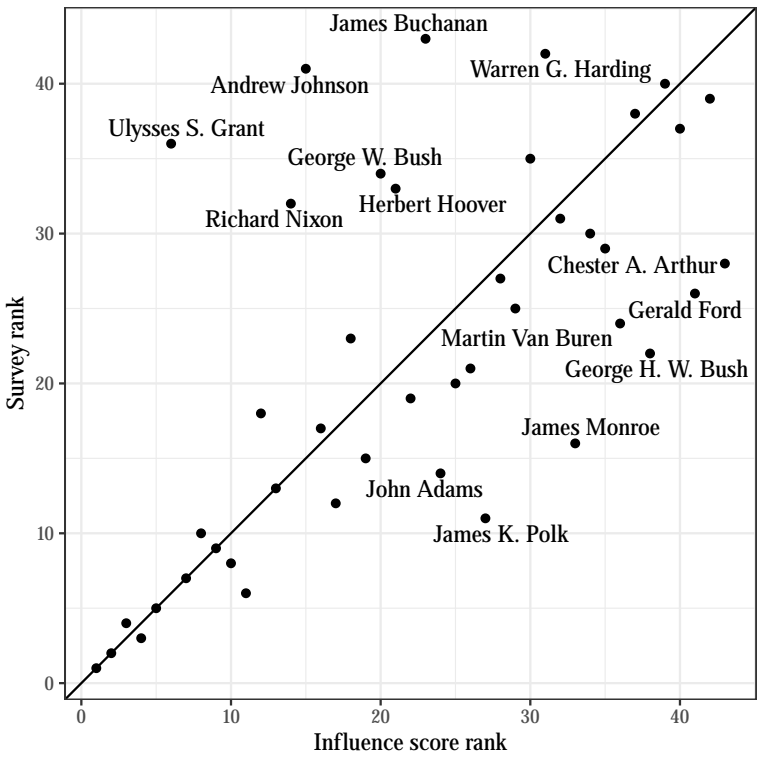

Note: Only outliers with a difference in ranks $>10$ are labeled.

rankings). It turns out that the rank correlation between the average survey-based ranking and the Wikipedia-based rankings is higher for the influence measure $(\rho=0.59)$ than for the prominence measure $(\rho=0.50)$. This is plausible, as the latter is expected to be more heavily influenced by contemporary attention and therefore more biased towards recent presidents, whereas the survey measures cover a time span of more than 6o years and are meant to map achievements that are less dependent on the zeitgeist.

The left panel in Figure 3, which plots the survey-based against the influence score ranks, indicates that there is still a substantive bias in the influence variable that works in favor of more recent presidents. To alleviate this property of the measure, I employ the simple correction strategy of regressing the estimated scores on a quadratic polynomial of the running index, allowing for a non-linear relationship between the influence score and the timing of the presidency, and then extract the residuals. This model alone explains 56 percent of the variance, and both early as well as recent presidents then score systematically higher on the influence measure. 5 The results of these "time-debiased" ranks are plotted

\footnotetext{
${ }^{5}$ Complete model results are reported in Table B6 in the Online Appendix (p. 5).
} 
against the survey ranks in the right panel of Figure 3 . The correlation between both measures has increased $(\rho=0.65)$. The agreement between both measures is particularly large for the high-ranking presidents (lower-left corner), Ulysses S. Grant being the only exception. The other outliers-particularly in the upper triangle-are less surprising and reflect the substantive differences of the measures: ${ }^{6}$ In contrast to the expert rankings, scores of influence are rather agnostic towards the quality of achievements. Another take-away of this exercise is that while the Wikipedia data cannot be seen as independent of the zeitgeist of the era in which they are generated, cross-time comparisons of influence scores can be justified after statistically accounting for recency bias.

\section{Human judgments based on MTurk ratings}

In more extensive efforts to establish construct validity, I continue by comparing the generated factor scores with a source of human judgement that is tailored towards the measured concepts. More specifically, I present results from a rating exercise implemented on the crowdsourcing platform Amazon Mechanical Turk (MTurk). A sample of experienced MTurk workers was presented with multiple pairs of politicians and then select the one that presented the better fit for a certain criterion.

Two samples of politicians serve as the basis for the pairwise comparisons, that being all 44 U.S. presidents, as well as a subset of 99 members of the 115th Congress. The procedure to draw the samples and build the pairs for tasks is described in more detail in Online Appendix D (p. 11).

Workers judged which of two politicians they considered to (a) be better known in the American public, (b) be seen more favorably in the American public, and (c) have had more impact in shaping American politics. Tasks (a) and (c) are thought to serve as a concurrent validity criterion for the prominence and influence measures. Task (b) reflects a trait that is not meant to be captured directly by the Wikipedia-based measures and serves as a criterion for discriminant validity. For each of the tasks, raters had to judge five pairs of

\footnotetext{
${ }^{6}$ Both Johnson and Buchanan have consistently ranked among the worst presidents in U.S. history, but have achieved dubious fame-the former through being in constant war with Congress and impeached by the House, the latter through failing to address the issues of slavery and secession on the eve of the Civil War.
} 
U.S. presidents and 15 pairs of members of Congress. All in all, 2,000 comparisons per task and 6,000 comparisons in total were collected. Within each task, a unique pair was assigned to 4.6 raters on average (see Table D8 in Online Appendix D (p. 14) for more task and rater statistics).

To arrive at scores for each of the measured traits, I estimated a Bayesian variant of the Bradley-Terry model (Bradley and Terry, 1952) that allows for fitting the model to sparse datasets with a comparison graph that is not fully connected (Caron and Doucet, 2012; Kaye and Firth, 2017). The Bradley-Terry model takes a set of $K$ items and models the probabilities for each item in the set to beat each of the other items as a function of item-specific parameters representing the "strength" of each item $k .{ }^{7}$

Agreement among raters, measured as the average of the majority opinion fraction on each comparison, varied between 72\% ("liked" trait of members of Congress) and 88\% ("well-known" trait of presidents). Figure 4 reports the correlations between the Wikipediabased measures and the MTurk based measures, separated by the sample of politicians. What is immediately obvious is that the correlations between the measures are generally fairly high, indicating that the Wikipedia scores are roughly in line with human judgments of politicians' importance. The individual correlations provide a more nuanced picture. Ideally, the correlations within traits should be high across methods (highlighted by dark-grey fields) and low across traits. The prominence scores are correlated with 0.8 in the "well-known" judgments in the U.S. Presidents sample, which is remarkable. It is somewhat lower within the Congress sample, partly due to the fact that this task involved many lesser-known politicians. The influence measure is correlated with the "impact" judgments at 0.71 in the Presidents sample and at 0.55 in the Congress sample, which is still fairly high. Compared with the other correlations, it is only partly possible to demonstrate that the measures are able to discriminate between traits. Recall, however, that this is a very difficult task given that the traits are expected to be highly correlated. The cor-

${ }^{7}$ More specifically, the probability of item $i$ beating item $j$ is modelled as $p_{i j}=\frac{\pi_{i}}{\pi_{i}+\pi_{j}}$, with $\pi_{k}$ representing the strength of item $k$. Denoting the number of times $i$ beats $j$ as $w_{i j}$, the log-likelihood for $\pi$ is $\mathrm{L}(\pi)=$ $\sum_{i=1}^{K} \sum_{j=1}^{K}\left[w_{i j}\left(\log \pi_{i}-\log \left(\pi_{i}+\pi_{j}\right)\right)\right]$. To identify the likelihood when $i-j$ comparisons are missing, a Gamma prior is placed on each $\pi_{i}$, and an EM algorithm is used to find the maximum a posteriori estimates of $\pi$ (see Caron and Doucet, 2012; Kaye and Firth, 2017). 
Figure 4: Correlations of MTurk-based importance estimates with Wikipedia measures.

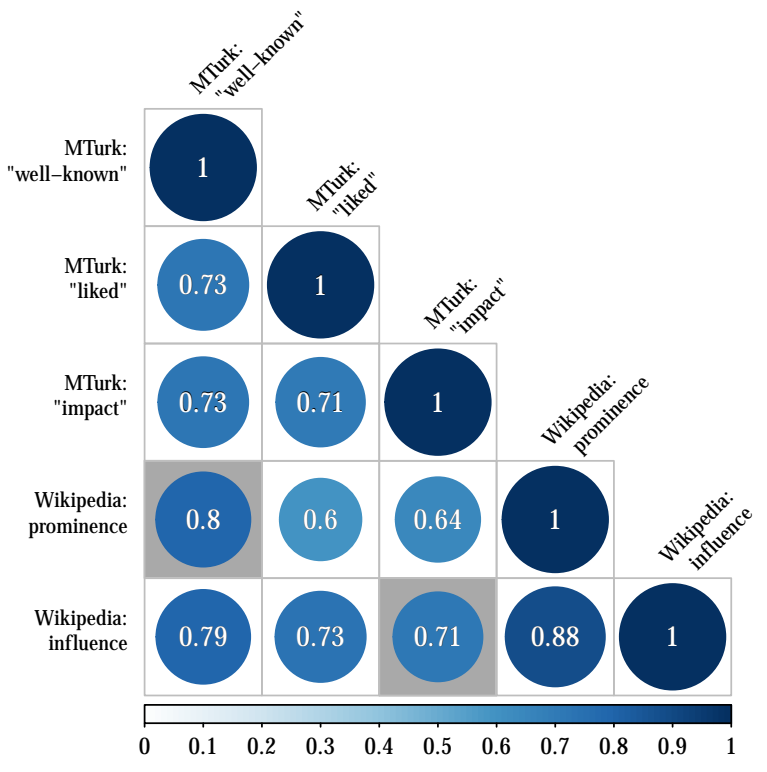

(a) US Presidents

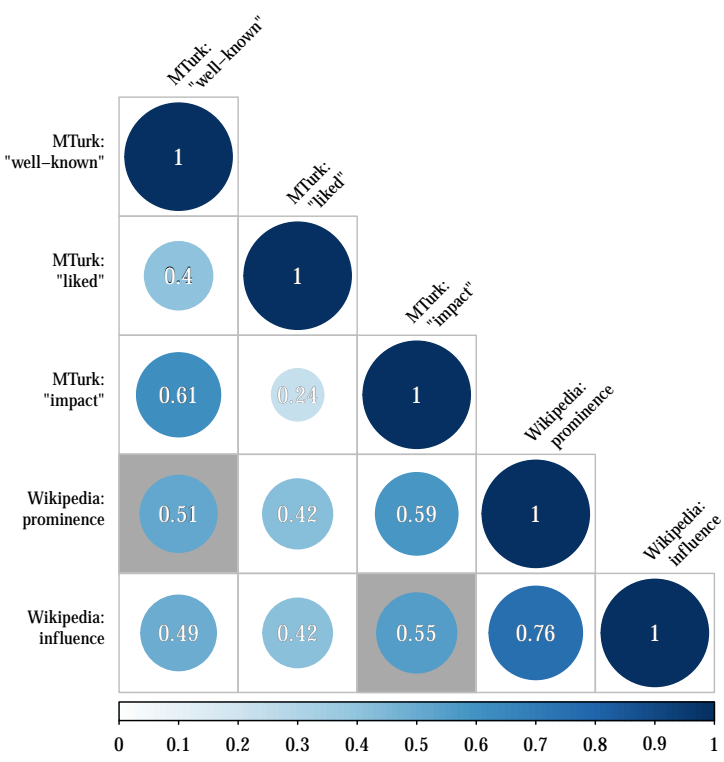

(b) Members of $115^{\text {th }}$ Congress

relations with the "liked" ratings are somewhat lower in the Congress sample (and, to a lesser extent, in the Presidential sample as well), indicating divergent validity.

In summary, the Wikipedia-based measures resonate rather well with human judgments. It remains difficult to tell, however, whether the distinction between dimensions with human raters is, in fact, possible. For the moment, this remains a feature of the new data that is hard to evaluate.

\section{Manifest characteristics of Members of Congress}

As a final validation effort, I explore the relationship with manifest indicators of political importance, as they are frequently used in the literature. These include previous political offices (e.g., Volden, Wiseman and Wittmer, 2013), (party) leadership positions in the chambers (e.g., Fouirnaies and Hall, 2018; Holbrook and Tidmarch, 1993), and seniority (e.g., Ban, Llaudet and Snyder Jr, 2016; Hall and Shepsle, 2013).

Figure 5 provides estimates from OLS models of prominence and influence based on 492 members of the 115th U.S. Congress. Predictors include chamber membership (House/Senate), the number of sessions served, party affiliation (Democrat/Republican/Inde- 
Figure 5: The relationship between alternative indicators of importance and prominence (grey) and influence (black) scores for Members of 115th Congress.

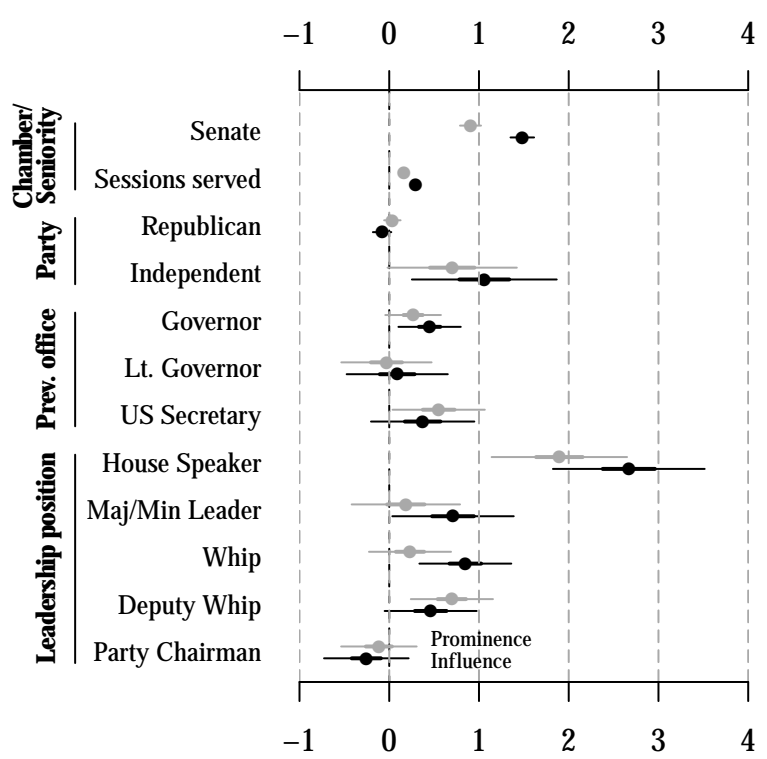

Note: OLS coefficients plotted along with $50 \%$ and $95 \%$ confidence bars. Prominence scores in the sample range from 0.55 to 5.03; influence scores from -0.03 to 7.68. Fit statistics for prominence model: $\mathrm{N}=492$, Residual $\mathrm{SD}=0.50, \mathrm{Adj} . R^{2}=$ 0.49; fit statistics for influence model: $\mathrm{N}=492$, Residual $\mathrm{SD}=$ 0.57 , Adj. $R^{2}=0.69$.
Figure 6: Outliers on predicted prominence.

\begin{tabular}{rccc}
\hline Name & Chamber & Score & Residual \\
\hline Charlie Crist & House & 3.82 & 1.88 \\
Al Franken & Senate & 4.52 & 1.75 \\
John McCain & Senate & 5.03 & 1.59 \\
Lee Zeldin & House & 3.33 & 1.55 \\
Marco Rubio & Senate & 4.30 & 1.51 \\
\hline D. Wasserman Schultz & House & 3.55 & 1.42 \\
Joe Wilson & House & 3.44 & 1.28 \\
Steve King & House & 3.36 & 1.26 \\
Elizabeth Warren & Senate & 4.04 & 1.22 \\
Anthony G. Brown & House & 2.77 & 1.20 \\
\hline
\end{tabular}

Figure 7: Outliers on predicted influence.

\begin{tabular}{rccc}
\hline Name & Chamber & Score & Residual \\
\hline John McCain & Senate & 7.68 & 3.20 \\
Charlie Crist & House & 4.22 & 2.17 \\
Elizabeth Warren & Senate & 5.28 & 1.91 \\
Darrell Issa & House & 4.14 & 1.83 \\
Marco Rubio & Senate & 4.94 & 1.64 \\
\hline Al Franken & Senate & 5.08 & 1.62 \\
Rand Paul & Senate & 4.74 & 1.43 \\
D. Wasserman Schultz & House & 3.71 & 1.43 \\
Justin Amash & House & 3.17 & 1.34 \\
Jared Polis & House & 3.28 & 1.30 \\
\hline
\end{tabular}

pendent), and a set of binary indicators for high-profile offices held by the representative before they joined Congress, as well as for leadership positions in both chambers.

The chamber membership variable as well as the tenure indicator, which counts the number of sessions served, both turned out to be strong predictors. On average, Senators are substantively more important on both dimensions than House members (and to a greater extent on the influence dimension). The same applies for more senior politicians. Party membership does not seem to play a major role, although Independents do score higher on both dimensions (but notice the large standard errors due to the fact that there are only three Independents in the sample). In terms of previous political offices, high-profile posts such as State Governor or U.S. Secretary are positively associated with both importance dimensions, whereas Lieutenant Governors are on average neither more prominent nor influential. Leadership positions do tend to matter, particularly with regards to influence. This is not the case for the position of the Party Chairman, which is 
ranked lower than the other listed positions. A finding that further corroborates the validity of the measures is that being a party whip-an office serving the internal cohesion of the parties-is predictive of influence but not prominence.

The employed manifest indicators alone cannot fully explain the importance scores in the studied sample (adj. $R^{2}=0.49$ for the prominence and $R^{2}=0.69$ for the influence model). Assuming general convergent validity, this could be both due to noise in the Wikipedia-based scores and to the fact that the manifest indicators are insufficient in themselves to provide a high-resolution picture of importance. The outliers of the models' predictions are indicative of the latter. Figures 6 and 7 list the ten observations with the highest residuals each from the OLS models (politicians which influence and prominence scores are underestimated by the models).

The lists appear rather similar. Featured on both is, for instance, Charlie Crist, former Governor of Florida, who switched parties in 2010 and became Representative for Florida's 13th district in 2017. His unorthodox career and ties in both major parties as well as highly noticed campaigns against other high-profile candidates, which are not fully picked up by the hard measures, give the Wikipedia-based scores some face validity. Other examples are high-profile Democrat Elizabeth Warren, who is plausibly estimated to be much more influential that the manifest criteria would tell, as well as the late John McCain, one of the most senior and influential contemporary political figures-though equipped with little formal power.

Overall, the comparison shows that while the importance scores are fairly strongly associated with many of the manifest indicators variables, they cannot be fully substituted. Instead, they help identify meaningful variation in a sample of high-profile politicians, which is something an approach merely based on manifest indicators is doomed to fall short of.

In addition to higher precision in measurement, there are additional reasons to prefer the Wikipedia-based scores over manifest indicators: First, using the compound measure saves degrees of freedom as the researcher needs to employ just one variable (or two, if both importance dimensions are studied) instead of multiple office and seniority indicators, as is often done in models of elite behavior. Second, the measures make comparisons 
across legislative or executive bodies more straightforward, as they are constructed from one joint database and do not require individual coding of offices, positions, or seniority. Finally, the choice of manifest measures in the literature is often ad hoc, with little theoretical reasoning provided of why one indicator is preferred over another. Here, I offer a measure that is both theoretically founded and put to multiple validation tests.

\section{Application: Coverage Bias in Political News}

I now go on to showcase the use of the suggested measures for substantive research in a small example application. A question which has received attention recently is the role of the news media in the personalization of politics and political campaigns (e.g., Banducci et al., 2018; Holtz-Bacha, Langer and Merkle, 2014). Previous research provides evidence for coverage bias that works in favor of legislators who hold leadership positions, are senior, and belong to the party in power (Green-Pedersen, Mortensen and Thesen, 2017; Tresch, 2009). This is hardly surprising because these characteristics per se provide news value. With the new measures at hand, it is possible to shed more light on this relationship: First, their continuous nature allows for studying the functional form of the relationship. Second, it is possible to disentangle whether political influence or public prominence is more predictive for media coverage.

As a proxy of media attention towards political elites, I collected data on mentions of elected members of the 115th Congress in eight major media sources between February and September 2018. ${ }^{8}$ I then constructed a variable that counts the number of articles in which a legislator was mentioned at least once. The average number of mentions in all outlets combined was 112. Just seven (1.5\%) of the members were not mentioned at all, $89 \%$ more than five times. $21 \%$ percent were mentioned 100 times or more.

Figure 8 plots influence as well as prominence scores of all members against their coverage in the newspapers. The plots suggest that news coverage can be modeled using an

\footnotetext{
${ }^{8}$ Using the Mediacloud API, which allows full-text searches of given keywords, I searched for all legislators' names appearing in any part of the article in one of the following outlets: New York Times, Washington Post, USA Today, LA Times, NY Post, Daily News, Chicago Tribune, and Houston Chronicle. The time range was chosen to avoid overlap with the data collection period for the Wikipedia-derived scores, which could induce an immediate feedback loop of media coverage on Wikipedia consumption.
} 
Figure 8: News coverage vs. prominence and influence scores of Members of 115th U.S. Congress

(a) Prominence

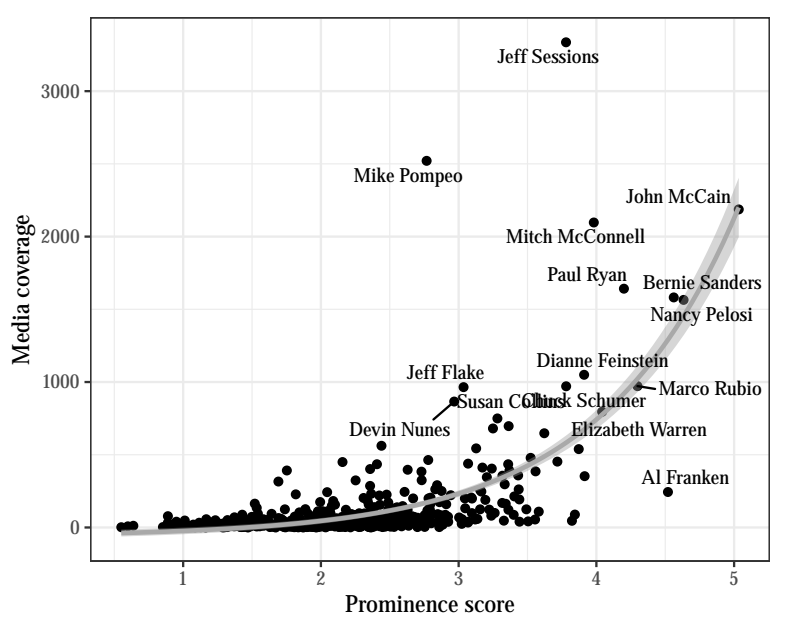

(b) Influence

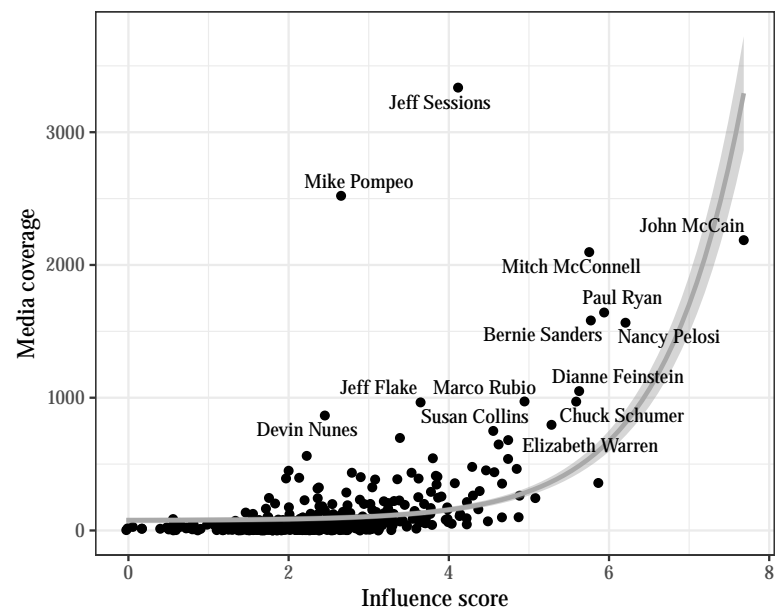

Note: The grey lines represent an exponential fit.

exponential function of both influence and prominence. In fact, an exponential model fitted with no covariates other than the prominence score explains $44 \%$ of the variance (29\% if the influence score is used, which is mostly due to the influential outlier McCain).

For a more systematic assessment of what drives the inequality in news coverage, I run a set of negative binomial regressions with the number of mentions as the dependent variable. In addition to the importance measures, I include a set of manifest indicators similar to those employed in the previous validation exercise.

Table 1 reports the results of four specifications, (1) including the manifest indicators only, (2) adding the exponentiated prominence score, (2) adding the exponentiated influence score, and (4) the full model. Perhaps unsurprisingly, the models show that members of the Senate, members of the governing party (Republicans), and those who became part of the Trump administration or those held another leadership position received significantly more coverage, whereas gender and having held a high-profile office prior to the period under consideration do not seem to matter. However, there is a part of prominence that is not picked up by the manifest features and that contributes substantively to the coverage in the media, as mirrored in the coefficient for the exponentiated prominence score. 
Table 1: The effects of legislator characteristics on media coverage

\begin{tabular}{|c|c|c|c|c|}
\hline & (1) & (2) & (3) & (4) \\
\hline Exp(Prominence) & & $\begin{array}{l}0.047^{* * *} \\
(0.004)\end{array}$ & & $\begin{array}{l}0.057^{* * *} \\
(0.006)\end{array}$ \\
\hline Exp(Influence) & & & $\begin{array}{l}0.005^{* * *} \\
(0.0005)\end{array}$ & $\begin{array}{l}-0.002^{* * *} \\
(0.001)\end{array}$ \\
\hline Male & $\begin{array}{l}-0.100 \\
(0.126)\end{array}$ & $\begin{array}{c}0.141 \\
(0.118)\end{array}$ & $\begin{array}{l}-0.005 \\
(0.123)\end{array}$ & $\begin{array}{c}0.156 \\
(0.118)\end{array}$ \\
\hline Senate & $\begin{array}{l}1.693^{* * *} \\
(0.126)\end{array}$ & $\begin{array}{l}0.985^{* * *} \\
(0.131)\end{array}$ & $\begin{array}{l}1.371^{* * *} \\
(0.127)\end{array}$ & $\begin{array}{l}0.981^{* * *} \\
(0.132)\end{array}$ \\
\hline Sessions served & $\begin{array}{l}0.056^{* * *} \\
(0.011)\end{array}$ & $\begin{array}{c}0.016 \\
(0.011)\end{array}$ & $\begin{array}{l}0.036^{* * *} \\
(0.011)\end{array}$ & $\begin{array}{c}0.017 \\
(0.010)\end{array}$ \\
\hline Independent & $\begin{array}{l}1.075 \\
(0.634)\end{array}$ & $\begin{array}{c}-1.132 \\
(0.610)\end{array}$ & $\begin{array}{l}-0.128 \\
(0.624)\end{array}$ & $\begin{array}{l}-1.121 \\
(0.609)\end{array}$ \\
\hline Republican & $\begin{array}{l}0.396^{* * *} \\
(0.103)\end{array}$ & $\begin{array}{l}0.259^{* *} \\
(0.096)\end{array}$ & $\begin{array}{l}0.343^{* * *} \\
(0.101)\end{array}$ & $\begin{array}{l}0.259^{* *} \\
(0.096)\end{array}$ \\
\hline Prev. high-profile office & $\begin{array}{c}-0.013 \\
(0.283)\end{array}$ & $\begin{array}{c}-0.268 \\
(0.265)\end{array}$ & $\begin{array}{c}-0.043 \\
(0.277)\end{array}$ & $\begin{array}{c}-0.315 \\
(0.264)\end{array}$ \\
\hline Leadership position & $\begin{array}{l}1.544^{* * *} \\
(0.258)\end{array}$ & $\begin{array}{r}0.533^{*} \\
(0.248)\end{array}$ & $\begin{array}{r}0.639^{*} \\
(0.255)\end{array}$ & $\begin{array}{r}0.635^{*} \\
(0.247)\end{array}$ \\
\hline Administration member & $\begin{array}{l}2.879^{* * *} \\
(0.512)\end{array}$ & $\begin{array}{l}2.583^{* * *} \\
(0.479)\end{array}$ & $\begin{array}{l}2.869^{* * *} \\
(0.501)\end{array}$ & $\begin{array}{l}2.523^{\text {** }} \\
(0.479)\end{array}$ \\
\hline Constant & $\begin{array}{l}3.317^{* * *} \\
(0.133)\end{array}$ & $\begin{array}{l}2.982^{* * *} \\
(0.127)\end{array}$ & $\begin{array}{l}3.326^{* * *} \\
(0.131)\end{array}$ & $\begin{array}{l}2.901^{* * *} \\
(0.132)\end{array}$ \\
\hline$\theta$ & 0.866 & 0.997 & 0.906 & 1.006 \\
\hline $\begin{array}{l}\text { Observations } \\
\text { Akaike Inf. Crit. }\end{array}$ & $\begin{array}{c}513 \\
5,360.306\end{array}$ & $\begin{array}{c}513 \\
5,275.899\end{array}$ & $\begin{array}{c}513 \\
5,334.203\end{array}$ & $\begin{array}{c}513 \\
5,272.425\end{array}$ \\
\hline
\end{tabular}

Notes: Negative binomial regression coefficients with standard errors in parentheses. Dependent variable is number of times mentioned in eight major print media outlets between February and September 2018. ${ }^{*} \mathrm{p}<0.05 ;{ }^{* *} \mathrm{p}<0.01 ;{ }^{* * *} \mathrm{p}<0.001$, two-tailed tests.

On the other hand, the positive association of influence on coverage is mostly sucked up by the other variables. To illustrate the implications of model (4), a male, Republican member of the House with a prominence score of 4 (about 1.5\% in the sample have a higher score), is expected to receive about $1280 \%$ more coverage than a person with the median prominence score of 2 (1212 vs. 88 expected mentions). This is an advantage similar to a person being a member of the Administration but with a median number of sessions served and median levels of prominence and influence, who is expected to receive about $1140 \%$ more coverage (1092 vs. 88 expected mentions). 
Overall, the results corroborate previous findings, speaking to the "principle of cumulative inequality" (Wolfsfeld, 1997): Those who are already in exposed positions or can be considered prominent for other reasons are granted a privileged voice in the news, and those who would need it most have difficulties obtaining it. The data indicates that news coverage can be roughly approximated with an exponential fit to prominence. Furthermore, even when accounting for formal and latent indicators of political influence, prominence remains a substantive predictor. Of course, this is almost tautological, as media coverage can be expected to be a core driver of prominence.

\section{Discussion}

Using Wikipedia as a basis for measuring political importance is not without limitations. The platform is subject to constant change, which is simultaneously a disadvantage and advantage. When employing the measures, it is important to document which version of the data was utilized, e.g., by providing the date when article snapshots were retrieved and a date range for which page views or edit statistics were calculated. Fortunately, the APIs provide full access to all article versions that existed. On the other hand, political importance is time-variant: Politicians can gain nation-wide prominence overnight and almost as quickly sink into obscurity again. Wikipedia is famous for its editors, who often outpace traditional media in updating the articles as soon as new information becomes available. These patterns will reflect sudden changes in prominence better than traditional proxies, such as survey-based name recognition or office-based indicators.

The data is also shaped by the fact that it is a derivative of a crowdsourced editing effort. While the very idea of the suggested approach builds on the variation in the comprehensiveness of articles, factors other than political prominence or influence can affect whether and to what extent politicians are covered on the platform. Although thought of as a global repository of knowledge, it is biased towards English-speaking and Western world content (Callahan and Herring, 2011). The analysis presented here focused on the English Wikipedia, where almost all high-profile politicians (including historical figures) that held a political office in the United States have their own entry. Although specific language edi- 
tions tend to provide better coverage for political entities with the same official language (e.g., Polish politicians on the Polish Wikipedia), editions besides English often have a much smaller population of editors, resulting in fewer articles and editing activity. This must be accounted for when conducting comparative analysis with the data.

Furthermore, while the coverage of Wikipedia outstrips most other existing databases that have been used to quantify quality-related features of political characters, it still represents a highly selective sample. Politicians who are or were active in national-level institutions are more likely to be covered than state-level or local representatives. Generally, Wikipedia's notability guideline states that in order to be considered for a stand-alone article, a topic has to have received "significant coverage in reliable sources that are independent of the subject" (Wikipedia, 2018).

Women are also known to be under-represented on the platform (Reagle and Rhue, 2011; Wagner et al., 2015), not least because editors of the platform tend to be male (Hill and Shaw, 2013). This does not necessarily imply that the importance of female political elites is underestimated using these data, but instead that it is likely that there is a difference in coverage between politicians of different gender, thereby discounting less prominent women.

Various scholars of the platform have pointed to the problem of recency bias, meaning that contemporary individuals tend to be covered more often and with greater detail than individuals from the far past (Royal and Kapila, 2009; Skiena and Ward, 2013). However, a driving idea of the suggested approach is that it is exactly the attention towards articles that reflects contemporary prominence. Therefore, the phenomenon might not skew the measure but instead help account for the fact that people pay more attention to contemporary politicians than to historical figures. In practice, this bias should be negligible if the interest is in contemporary politicians, but it will become more problematic for analyses of political importance across time. On the other hand, the way the PageRank measures are constructed works against recency bias: It is more plausible that articles on contemporary politicians link to historical figures than the other way round, simply because legacy only works in one direction of time. 
To sum up, the Wikipedia-based measures should not be used blindly nor should the measurement approach be applied to other contexts without further validation efforts. That said, the validation results presented here are encouraging evidence for the usefulness of the data.

\section{Conclusion}

The paper presents a new way to measure the importance of political elites for a vast number of individuals at virtually no cost. Political importance is considered to be the combination of prominence, subsuming characteristics that contribute to the popular perception of politicians, as well as influence, describing how well politicians are connected among their peers and their footprint in the political arena.

As a consequence of how Wikipedia content is generated and consumed, its metadata provide robust indicators of these traits. The information to generate these measures can be accessed at no cost from the Wikipedia APIs. The technical burden to work with these data is minimized by providing readily available code that can be used to access and process these data, as well as published influence and prominence scores for the a comprehensive sample of U.S. politicians.

The ability to measure distinct dimensions of political importance for a large set of political elites has various implications for our understanding of political career paths, legislative politics, and electoral performance. It first helps in assessing the historical influence of political figures. Countless efforts have compiled rankings of "greatest politicians" or "political leaders" in history, which reflects the scholarly and public interest in the quest to decipher the more significant politician (e.g., Eland, 2009; Schlesinger Jr., 1997). These rankings typically focus on heads of state, which disregards the nature of many democratic systems, where opposition leaders, ministers etc. can hold a position which is powerful similar to others who are, formally speaking, ranked higher. The measure allows scholars to attain a more complete picture of historical importance.

In addition, political importance has immediate implications for political processes, such as agenda setting (Ban, Llaudet and Snyder Jr, 2016; Blumenau, 2018) policy-making 
(Hitt, Volden and Wiseman, 2017; Woon, 2008), or electoral campaigning (Kam and Zechmeister, 2013). Many electoral systems around the world feature personalized components where candidates have strong incentives to advertise themselves and become known among voters. While the valence literature claims that voters judge candidates based on characteristics such as integrity or competence, one could argue that, from a voter's perspective, personal character is just as difficult to assess as policy positions. Instead, voters might rely on more simple cues, such as whether they perceive a candidate as prominent or not.

Finally, political importance is an outcome which is, per se, worth studying: while holding formal positions (e.g., being a cabinet member or taking a major party office) guarantees attention by the media and vests politicians with extraordinary power, it is less clear how individuals achieve notability in the first place on their way from a freshman to a figure of importance in national politics. Linking the measure with data on personal, electoral, and institutional characteristics could help identify the impact of such factors on a politician's importance. 


\section{References}

Abramowitz, Alan. 1988. "Explaining Senate Election Outcomes." American Political Science Review 82(2):385-403.

Andersen, Peter A. and Robert J. Kibler. 1978. "Candidate valence as a predictor of voter preference.” Human Comunication Research 5(1):4-14.

Ban, Pamela, Alexander Fouirnaies, Andrew B. Hall and James M. Snyder. 2018. "How Newspapers Reveal Political Power." Political Science Research and Methods $\mathrm{XX}(\mathrm{XX}): 1-18$.

Ban, Pamela, Daniel Moskowitz and James M. Snyder. 2016. "Leadership Power in Congress, 1890-2014: Evidence from PAC Contributions and Newspaper Coverage." Unpublished Manuscript. http://dx.doi.org/10.2139/ssrn.2765092.

Ban, Pamela, Elena Llaudet and James M Snyder Jr. 2016. "Challenger quality and the incumbency advantage.” Legislative Studies Quarterly 41(1):153-179.

Banducci, Susan, Iulia Cioroianu, Travis Coan, Gabriel Katz and Daniel Stevens. 2018. "Intermedia agenda setting in personalized campaigns: How news media influence the importance of leaders.” Electoral Studies 54(2):281-288.

Blumenau, Jack. 2018. "Measuring Agenda-Setting Influence from Legislative Speech.” Unpublished Manuscript. https://www.jackblumenau.com/papers/influence.pdf.

Bonica, Adam. 2013. "Ideology and Interests in the Political Marketplace." American Journal of Political Science 57(2):294-311.

Bradley, Ralph Allan and Milton E. Terry. 1952. "Rank Analysis of Incomplete Block Designs: I. The Method of Paired Comparisons.” Biometrika 39(3/4):324-345.

Bratton, Kathleen A. and Stella M. Rouse. 2011. "Networks in the Legislative Arena: How Group Dynamics Affect Cosponsorship.” Legislative Studies Quarterly 36(3):423-460.

Brin, Sergey and Larry Page. 1998. The Anatomy of a Large-Scale Hypertextual Web Search Engine. In Proceedings of the 7th World-Wide Web Conference. Brisbane, Australia: pp. 1-20.

Buttice, Matthew K. and Walter J. Stone. 2012. "Candidates Matter: Policy and Quality Differences in Congressional Elections." The Journal of Politics 74(3):870-887. 
Callahan, Ewa S. and Susan C. Herring. 2011. "Cultural bias in Wikipedia content on famous persons." Journal of the American Society for Information Science and Technology 62(10):1899-1915.

Caron, Francois and Arnaud Doucet. 2012. "Efficient Bayesian Inference for Generalized Bradley-Terry Models.” Journal of Computational and Graphical Statistics 21(1):174196.

Clinton, Joshua D. 2006. "Representation in Congress: constituents and roll calls in the 106th House." The Journal of Politics 68(2):397-409.

Cohen, Jeffrey E. 2003. "The polls: Presidential greatness as seen in the mass public: An extension and application of the Simonton model." Presidential Studies Quarterly 33(4):913-924.

Cohen, Jonathan, Yariv Tsfati and Tamir Sheafer. 2008. "The Influence of Presumed Media Influence in Politics. Do Politicians' Perceptions of Media Power Matter?” Public Opinion Quarterly 72(2):331-344.

Cohen, Marty, David Karol, Hans Noel and John Zaller. 2009. The party decides: Presidential nominations before and after reform. University of Chicago Press.

Eland, Ivan. 2009. Recarving Rushmore: Ranking the Presidents on Peace, Prosperity, and Liberty. Oakland: Independent Institute.

Eom, Young-Ho and Dima L Shepelyansky. 2013. "Highlighting entanglement of cultures via ranking of multilingual Wikipedia articles." PloS one 8(10):e74554.

Fong, Christian, Neil Malhotra and Yotam Margalit. 2017. "Political Legacies.” Unpublished Manuscript. http://dx.doi.org/10.2139/ssrn.3028390.

Fouirnaies, Alexander and Andrew B. Hall. 2015. "The Power of Legislative Leaders." Unpublished Manuscript. http://www.andrewbenjaminhall.com/Fouirnaies_Hall_ Leaders.pdf.

Fouirnaies, Alexander and Andrew B. Hall. 2018. "How Do Interest Groups Seek Access to Committees?” American Journal of Political Science 62(1):132-147.

Fowler, James H. 2006. "Legislative cosponsorship networks in the US House and Senate." Social Networks 28(4):454-465. 
García-Gavilanes, Ruth, Milena Tsvetkova and Taha Yasseri. 2016. "Dynamics and biases of online attention: the case of aircraft crashes.” Royal Society Open Science 3(10).

Garzia, Diego. 2011. "The personalization of politics in Western democracies: Causes and consequences on leader-follower relationships." The Leadership Quarterly 22(4):697709 .

Gelman, Andrew. 2004. "Parameterization and Bayesian modeling." Journal of the American Statistical Association 99(466):537-545.

Giles, Jim. 2005. "Internet encyclopaedias go head to head." Nature 483(15 December):900-901.

Green-Pedersen, Christoffer, Peter B. Mortensen and Gunnar Thesen. 2017. "The Incumbency Bonus Revisited: Causes and Consequences of Media Dominance." British Journal of Political Science 47(1):131-148.

Hall, Andrew B. and Kenneth A. Shepsle. 2013. "The Changing Value of Seniority in the US House: Conditional Party Government Revised.” The Journal of Politics 76(1):98-113.

Hill, Benjamin Mako and Aaron Shaw. 2013. "The Wikipedia gender gap revisited: Characterizing survey response bias with propensity score estimation." PloS one 8(6):e65782.

Hitt, Matthew P., Craig Volden and Alan E. Wiseman. 2017. "Spatial models of legislative effectiveness.” American Journal of Political Science 61(3):575-590.

Holbrook, Thomas M. and Charles M. Tidmarch. 1993. "The Effects of Leadership Positions on Votes for Incumbents in State Legislative Elections." Political Research Quarterly 46(4):897-909.

Holtz-Bacha, Christina, Ana Ines Langer and Susanne Merkle. 2014. "The personalization of politics in comparative perspective: Campaign coverage in Germany and the United Kingdom.” European Journal of Communication 29(2):153-170.

Jacobson, Gary C. and Samuel Kernell. 1983. Strategy and Choice in Congressional Elections. New Haven: Yale University Press.

Kalla, Joshua L. and David E. Broockman. 2016. "Campaign Contributions Facilitate Access to Congressional Officials: A Randomized Field Experiment.” American Journal of Political Science 60(3):545-558. 
Kam, Cindy D. and Elizabeth J. Zechmeister. 2013. "Name Recognition and Candidate Support.” American Journal of Political Science 57(4):971-986.

Kaye, Ella and David Firth. 2017. BradleyTerryScalable: Fits the Bradley-Terry Model to Potentially Large and Sparse Networks of Comparison Data.

Lieberman, Michael D. and Jimmy Lin. 2009. "You are where you edit. Locating Wikipedia contributors through edit histories." third International AAAI Conference on Weblogs and Social Media (ICWSM'o9), San Jose, CA .

Merkle, Edgar C. and Ting Wang. 2016. "Bayesian latent variable models for the analysis of experimental psychology data." Psychonomic Bulletin \& Review 25(1):256-270.

Murphy, John M. and Mary E. Stuckey. 2002. "Never Cared to Say Goodbye: Presidential Legacies and Vice Presidential Campaigns.” Presidential Studies Quarterly 32(1):4666.

Murray, Robert K. and Tim H. Blessing. 1988. Greatness in the White House: rating the presidents, Washington through Carter; final report, the presidential performance study. Penn State University Press.

Norris, Pippa. 1997. Passages to Power: Legislative Recruitment in Advanced Democracies. Cambridge: Cambridge University Press.

Nyhuis, Dominic. 2016. "Electoral effects of candidate valence." Electoral Studies 42(1):33-41.

Ohmura, Tamaki, Stefanie Bailer, Peter Meissner and Peter Selb. 2017. "Party animals, career changers and other pathways into parliament.” West European Politics 41(1):169195 .

Plummer, Martyn. 2003. JAGS: A program for analysis of Bayesian graphical models using Gibbs sampling. In Proceedings of the 3rd International Workshop on Distributed Statistical Computing, ed. Kurt Hornik, Friedrich Leisch and Achim Zeileis. pp. 1-10.

Poole, Keith T. and Howard Rosenthal. 1985. "A Spatial Model for Legislative Roll Call Analysis." American Journal of Political Science 29(2):357-384.

R Core Team. 2017. R: A Language and Environment for Statistical Computing. Vienna, Austria: R Foundation for Statistical Computing. 
Rahat, Gideon and Tamir Sheafer. 2007. "The personalization (s) of politics: Israel, 19492003." Political Communication 24(1):65-80.

Ramey, Adam J., Jonathan D. Klingler and Gary E. Hollibaugh Jr. 2016. "Measuring Elite Personality Using Speech.” Political Science Research and Methods XX(XX):1-22.

Reagle, Joseph and Lauren Rhue. 2011. "Gender bias in Wikipedia and Britannica." International Journal of Communication 5:1138-1158.

Ripberger, Joseph T. 2011. "Capturing curiosity: using Internet search trends to measure public attentiveness.” Policy Studies Journal 39(2):239-259.

Royal, Cindy and Deepina Kapila. 2009. "What's on Wikipedia, and what's not...? Assessing completeness of information.” Social Science Computer Review 27(1):138-148.

Schlesinger, Arthur Meier. 1962. Our presidents: A rating by 75 historians. New York Times.

Schlesinger Jr., Arthur M. 1997. "Ranking the Presidents: From Washington to Clinton." Political Science Quarterly 112(2):179-190.

Skiena, Steven S. and Charles B. Ward. 2013. Who's Bigger?: Where Historical Figures Really Rank. Cambridge University Press.

Snyder, James M. 1992. "Long-term investing in politicians; or, give early, give often." The Journal of Law and Economics 35(1):15-43.

Thalhammer, Andreas. 2017. "Wikidata PageRank.” http://people.aifb.kit.edu/ath/.

Tresch, Anke. 2009. "Politicians in the media: Determinants of legislators' presence and prominence in Swiss newspapers." The International Journal of Press/Politics 14(1):67-90.

Volden, Craig, Alan E. Wiseman and Dana E. Wittmer. 2013. "When are women more effective lawmakers than men?” American Journal of Political Science 57(2):326-341.

Vrandečić, Denny and Markus Krötzsch. 2014. "Wikidata: A Free Collaborative Knowledgebase." Commun. ACM 57(10):78-85.

URL: $h t t p: / /$ doi.acm.org/10.1145/2629489

Wagner, Claudia, David Garcia, Mohsen Jadidi and Markus Strohmaier. 2015. "It's a Man's Wikipedia? Assessing Gender Inequality in an Online Encyclopedia." arXiv preprint arXiv:1501.06307. 
Wikipedia. 2018. "Wikipedia Notability Guideline.”.

URL: $\quad h t t p s: / / e n . w i k i p e d i a . o r g / w / i n d e x . p h p ? t i t l e=$ Wikipedia: Notability\&oldid= 821215172

Wikipedia Manual of Style. 2017.

URL: https://en.wikipedia.org/w/index.php?title=Wikipedia:Manual_of_Style/ Linking\&oldid $=791759470$

Wolfsfeld, Gadi. 1997. Media and political conflict: News from the Middle East. Cambridge University Press.

Woon, Jonathan. 2008. "Bill sponsorship in Congress: the moderating effect of agenda positions on legislative proposals." The Journal of Politics 70(1):201-216. 


\section{Measuring the Importance of Political Elites Online Appendix}

\section{Contents}

$\begin{array}{ll}\text { Appendices } & 1\end{array}$

$\begin{array}{lll}\text { Appendix A Model implementation } & 2\end{array}$

$\begin{array}{lll}\text { Appendix B Supporting tables and figures } & 3\end{array}$

Appendix C Applying PageRank to political elites on Wikipedia 9

$\begin{array}{ll}\text { Appendix D Amazon MTurk rating } & 11\end{array}$

$\begin{array}{ll}\text { Appendix E Software statement } & 18\end{array}$ 


\section{Appendix A Model implementation}

Figure A1: JAGS code for two-factor model with correlated factors

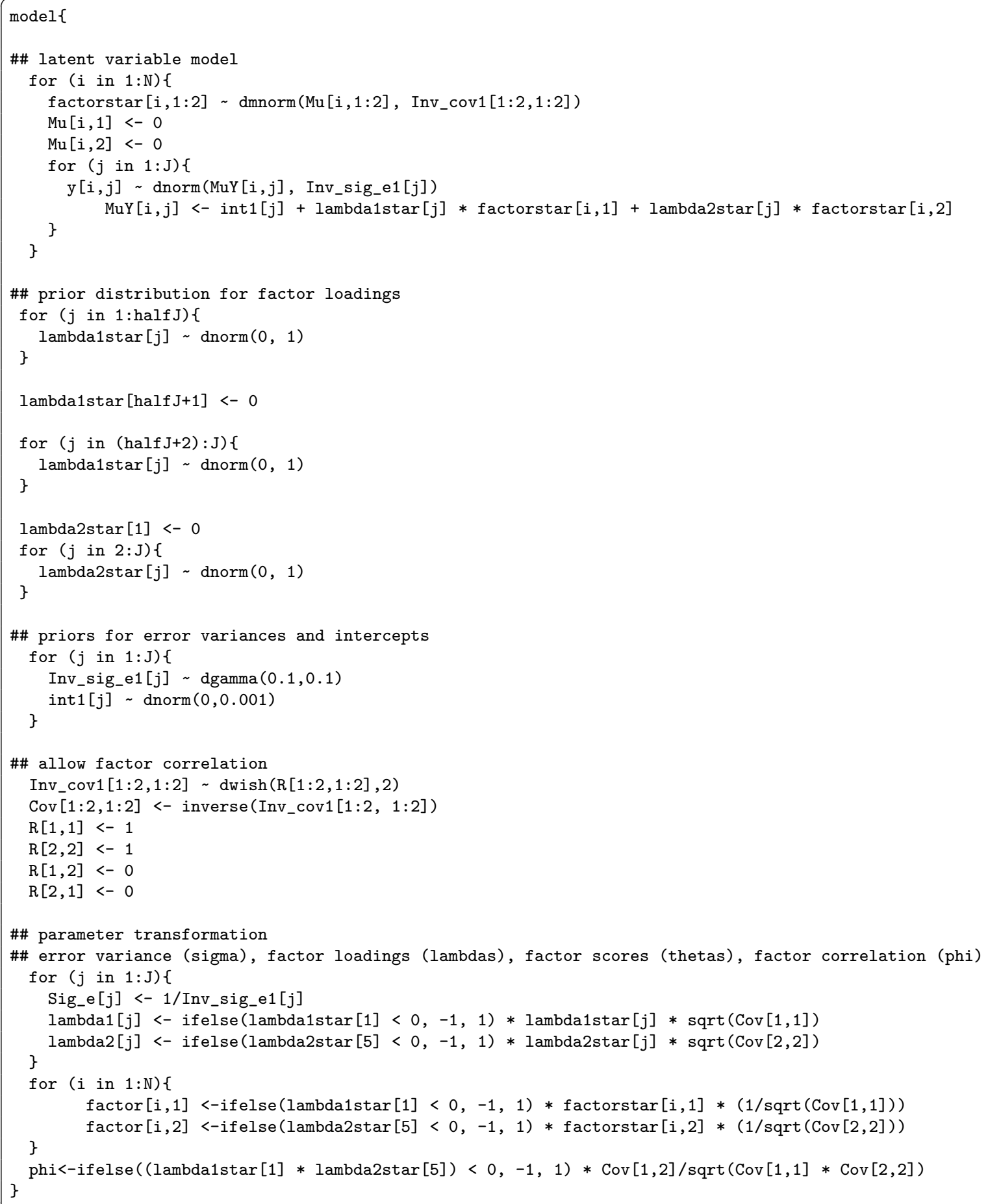




\section{Appendix B Supporting tables and figures}

Table B1: Summary statistics of utilized variables

\begin{tabular}{lccccc}
\hline Statistic & $\mathrm{N}$ & Mean & St. Dev. & Min & Max \\
\hline Revisions & 45,038 & 103.464 & 515.744 & 1 & 46,503 \\
Editors & 45,038 & 52.238 & 189.791 & 1 & 14,650 \\
Article size & 45,038 & $2,894.981$ & $5,462.900$ & 54 & 105,687 \\
Page views & 45,038 & 37.755 & 567.578 & 0.000 & $81,212.910$ \\
PageRank (global) & 45,038 & 0.454 & 3.027 & 0.150 & 253.822 \\
PageRank & 45,038 & 0.00002 & 0.0001 & 0.00001 & 0.007 \\
Language editions & 45,038 & 2.673 & 6.741 & 1 & 296 \\
\hline
\end{tabular}

Table B2: Summary statistics of utilized variables (logged)

\begin{tabular}{lccccc}
\hline Statistic & $\mathrm{N}$ & Mean & St. Dev. & Min & Max \\
\hline Revisions & 45,038 & 3.694 & 1.096 & 0.000 & 10.747 \\
Editors & 45,038 & 3.209 & 0.995 & 0.000 & 9.592 \\
Article size & 45,038 & 7.293 & 1.118 & 3.989 & 11.568 \\
Page views & 45,038 & 1.110 & 1.463 & -2.303 & 11.305 \\
PageRank (global) & 45,038 & -1.307 & 0.626 & -1.897 & 5.537 \\
PageRank & 45,038 & -11.470 & 0.847 & -12.024 & -4.985 \\
Language editions & 45,038 & 0.513 & 0.744 & 0.000 & 5.690 \\
\hline
\end{tabular}

Table B3: Estimated loadings from two-factor model.

\begin{tabular}{rcc}
\hline Variable & Factor 1 [95\% CI] & Factor 2 [95\% CI] \\
\hline Revisions & $1.1[1.09 ; 1.1]$ & o [0;0] \\
Editors & $0.84[0.84 ; 0.85]$ & $0.15[0.14 ; 0.15]$ \\
Article size & $0.83[0.81 ; 0.84]$ & $0.06[0.05 ; 0.07]$ \\
Page views & $0.66[0.64 ; 0.67]$ & $0.69[0.68 ; 0.71]$ \\
Language editions & $0.04[0.03 ; 0.05]$ & $0.58[0.57 ; 0.59]$ \\
PageRank & $0.04[0.03 ; 0.05]$ & $0.57[0.56 ; 0.58]$ \\
PageRank (global) & o [0;0] & $0.6[0.59 ; 0.6]$ \\
\hline
\end{tabular}


Figure B2: Pearson correlation matrix of Wikipedia-based indicators. Article basis is biographies of U.S. politicians on the English Wikipedia, as of January 2018. All indicator pairs demonstrate a fairly strong to very strong positive relationship. Articles which are manipulated by many editors also demonstrate a relatively higher number of revisions, tend to be longer, and are available in more language editions. They are linked to by a greater amount of additional articles on politicians as well as all articles in the English project, and are consumed by a larger audience.

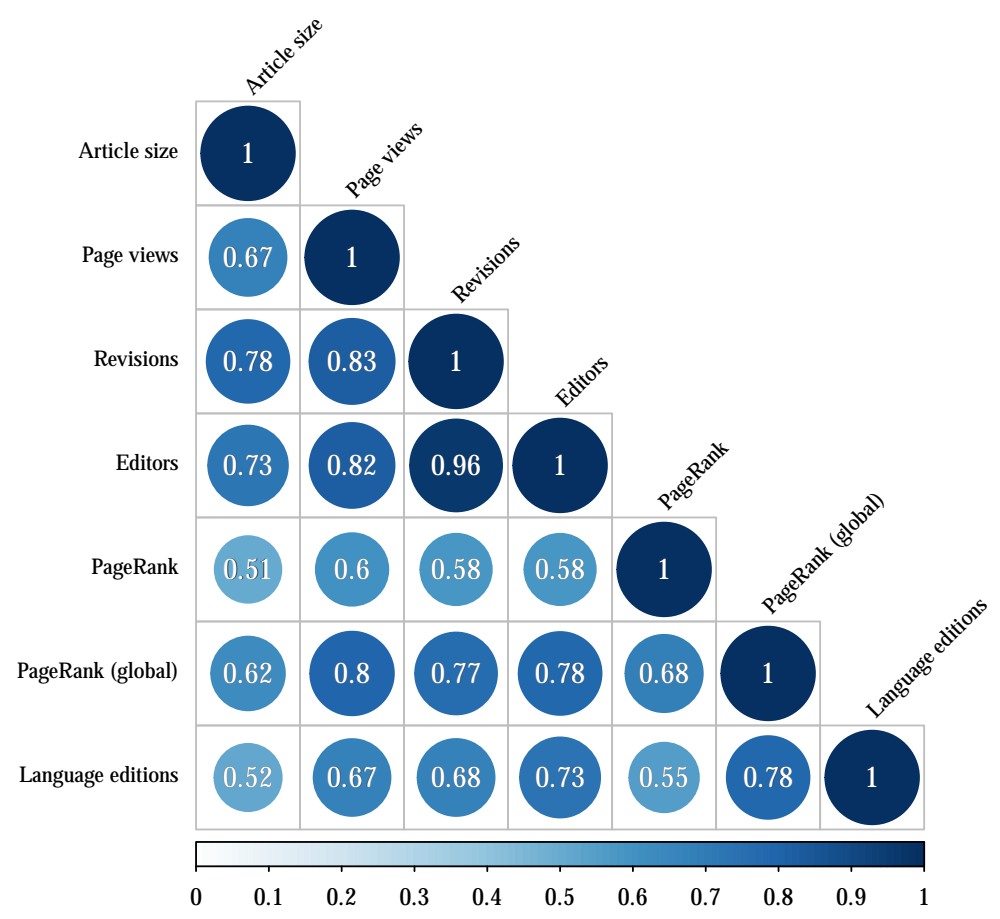

Table B4: Correlations of original prominence and influence measures with scores from reduced factor models.

\begin{tabular}{lccccc}
\hline & \multicolumn{2}{c}{ Prominence (full model) } & & \multicolumn{2}{c}{ Influence (full model) } \\
\cline { 2 - 3 } \cline { 5 - 6 } Variable dropped & Prominence & Influence & & Influence & Prominence \\
\hline Revisions & 0.973 & 0.781 & & 0.991 & 0.847 \\
Editors & 0.998 & 0.797 & & 0.996 & 0.794 \\
Article size & 0.997 & 0.796 & & 0.998 & 0.803 \\
Page views & 1.000 & 0.787 & & 0.995 & 0.787 \\
PageRank (global) & 1.000 & 0.783 & & 0.907 & 0.797 \\
PageRank & 1.000 & 0.800 & & 0.991 & 0.791 \\
Language editions & 1.000 & 0.794 & & 0.996 & 0.794 \\
\hline
\end{tabular}


Figure B3: Scree plot (Cattell, 1966) illustrating eigenvalues for one- to seven-factor models of Wikipedia-based indicators (solid line) and a random data matrix of the same size (dashed line; see Horn, 1965).

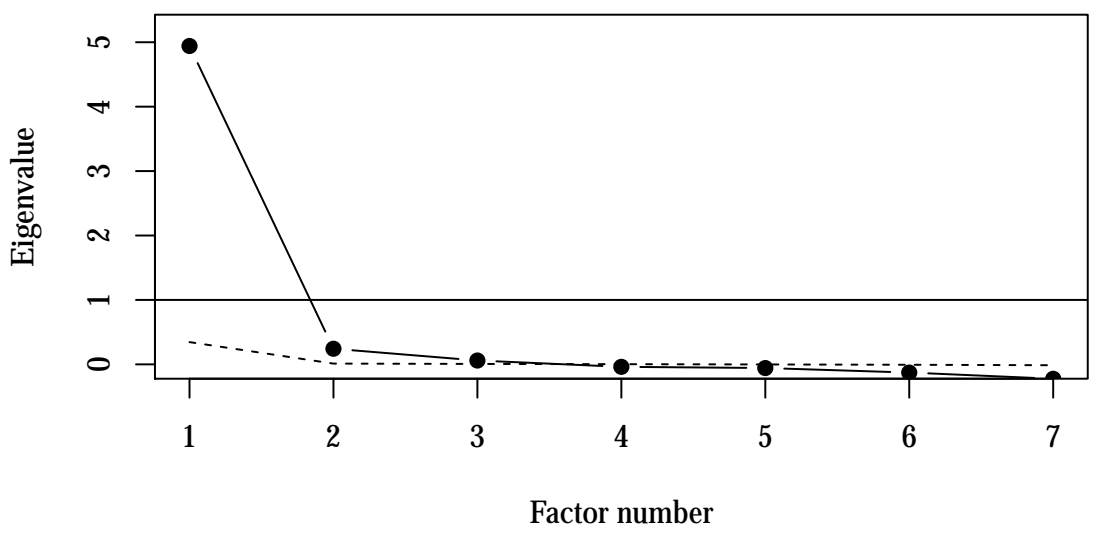

Table B5: Correlations of original prominence and influence measures with scores from factor models based on subsamples of politicians.

\begin{tabular}{|c|c|c|c|c|c|}
\hline \multirow[b]{2}{*}{ Sample } & \multirow[b]{2}{*}{$N$} & \multicolumn{2}{|c|}{ Prominence (full model) } & \multicolumn{2}{|c|}{ Influence (full model) } \\
\hline & & Prominence & Influence & Influence & Prominence \\
\hline Prominence $\operatorname{rank}<=1,000$ & 1000 & 0.998 & 0.754 & 0.988 & 0.780 \\
\hline Prominence rank in $] 1,000 ; 30,000]$ & 29000 & 1.000 & 0.731 & 0.983 & 0.732 \\
\hline Prominence rank $>=30,000$ & 15038 & 0.903 & 0.546 & 0.809 & 0.531 \\
\hline Congress members & 12249 & 0.999 & 0.873 & 0.993 & 0.872 \\
\hline Congress members, alive & 1538 & 0.998 & 0.863 & 0.992 & 0.820 \\
\hline
\end{tabular}

Table B6: OLS regressions of estimated factor scores on running indices of US presidents (George Washington $=1$, Barack Obama $=43$ ).

\begin{tabular}{lcc}
\hline & Prominence & Influence \\
\hline Index & $-0.068^{* * *}$ & $-0.125^{* * *}$ \\
& $(0.017)$ & $(0.036)$ \\
Index squared & $0.002^{* * *}$ & $0.004^{* * *}$ \\
& $(0.0004)$ & $(0.001)$ \\
(Intercept) & $5.125^{* * *}$ & $7.872^{* * *}$ \\
& $(0.167)$ & $(0.344)$ \\
$\mathrm{N}$ & 43 & 43 \\
$\mathrm{R}^{2}$ & 0.520 & 0.565 \\
Adjusted $\mathrm{R}^{2}$ & 0.496 & 0.543 \\
Residual Std. Error $(\mathrm{df}=40)$ & 0.352 & 0.723 \\
F Statistic $(\mathrm{df}=2 ; 40)$ & $21.662^{* * *}$ & $25.967^{* * *}$ \\
\hline
\end{tabular}

${ }^{*} \mathrm{p}<.1 ;{ }^{* *} \mathrm{p}<.05 ;{ }^{* * *} \mathrm{p}<.01$ 


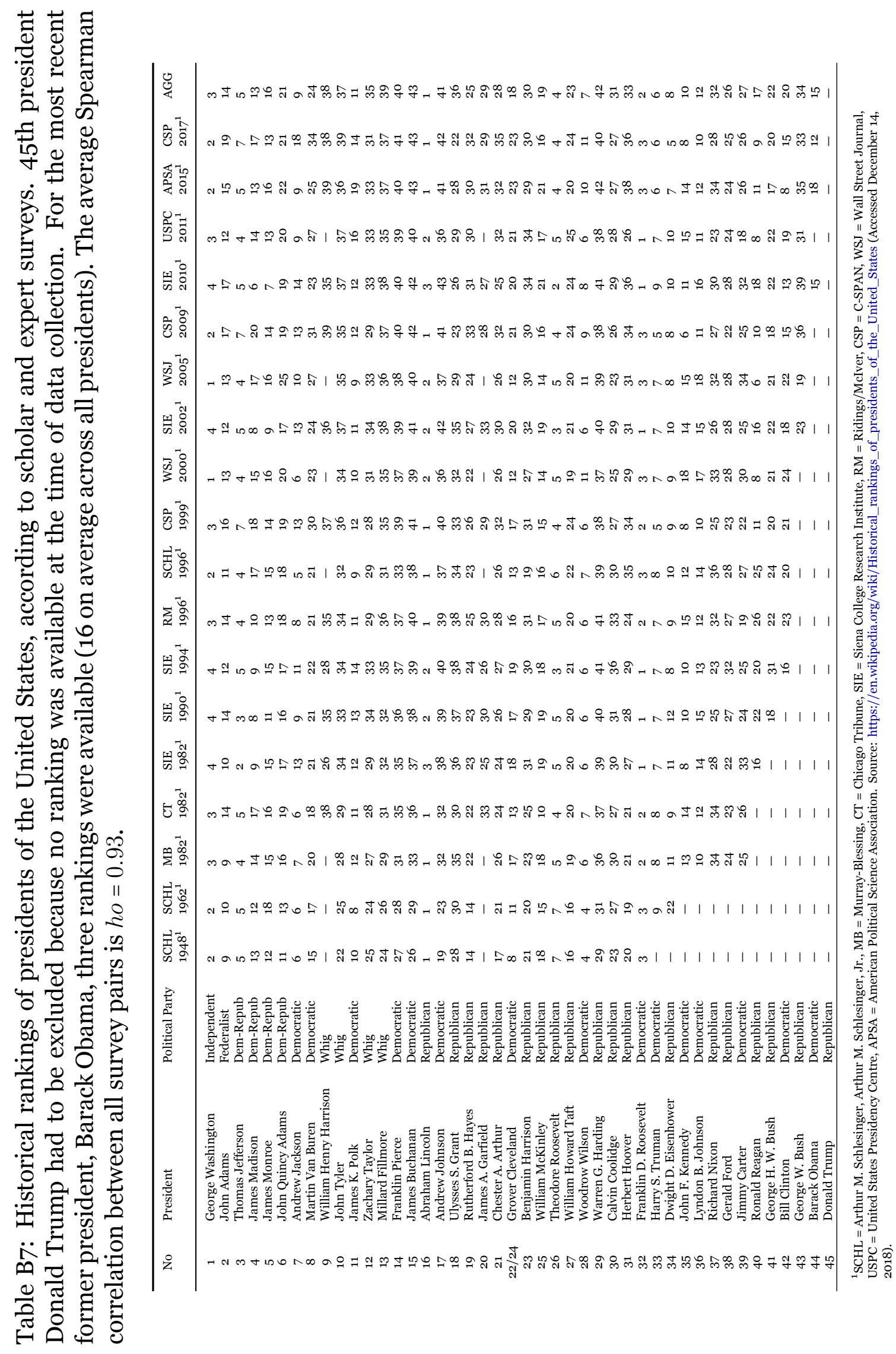


Figure B4: Distribution of estimated prominence and influence ranks for U.S. presidents

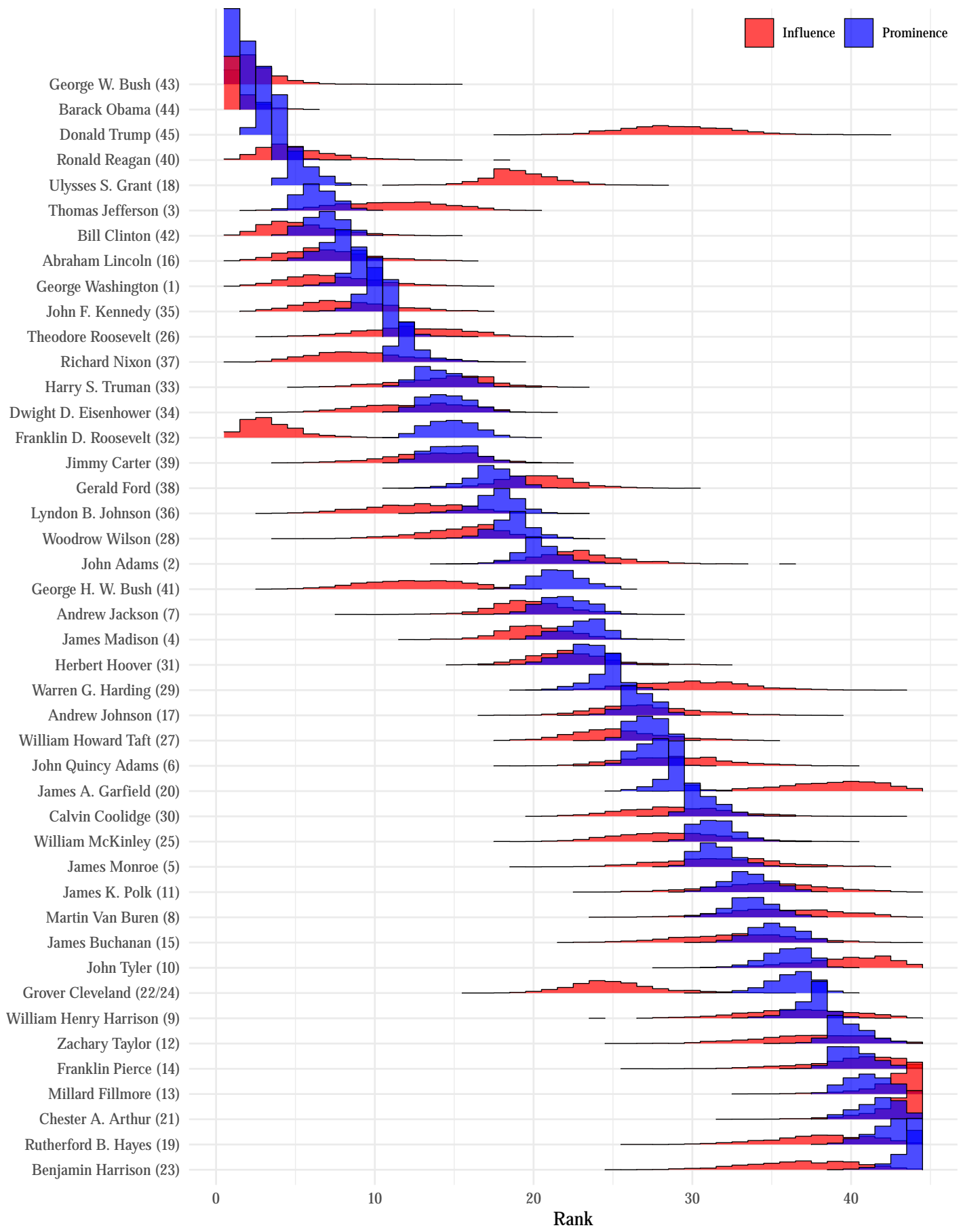

Note: Distributions based on 3,000 simulations. Presidents sorted by mean prominence rank. Numbers in parentheses indicate the order of incumbency. 
Figure B5: Estimated factor loadings from leave-one-variable-out specifications

(a) Variable dropped: Revisions

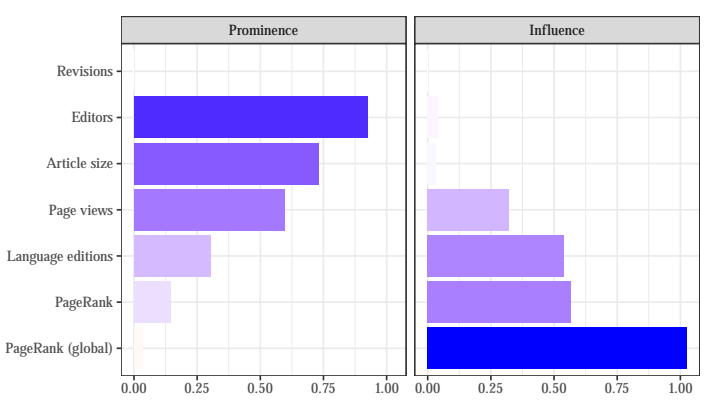

(c) Variable dropped: Article size

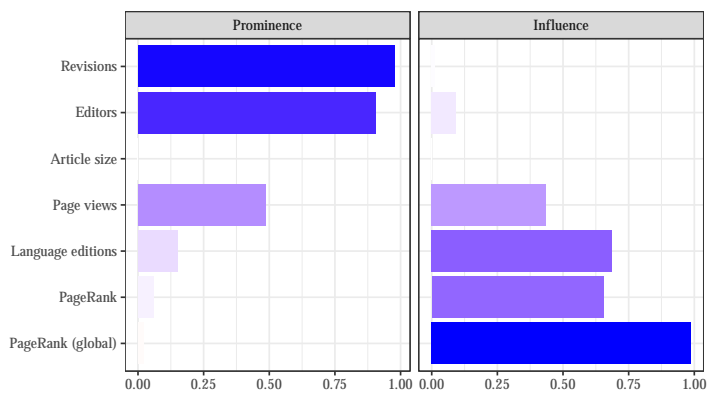

(e) Variable dropped: Language editions

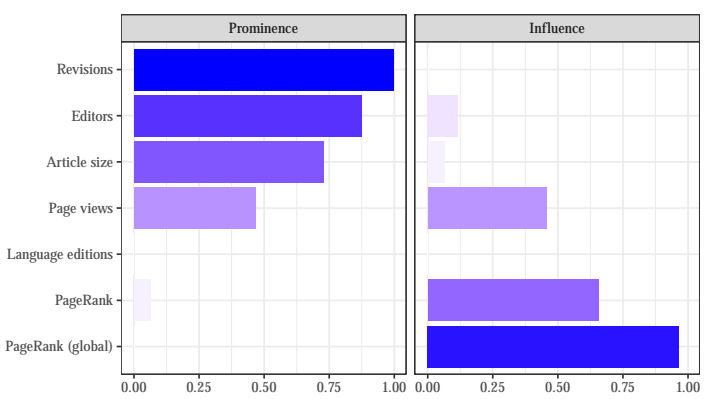

(g) Variable dropped: PageRank (global)

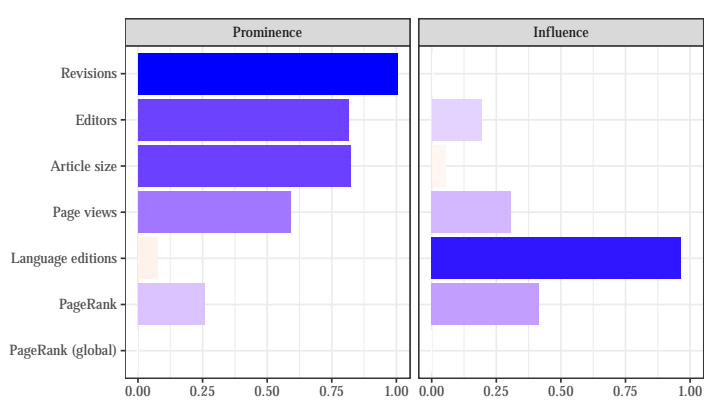

(b) Variable dropped: Editors

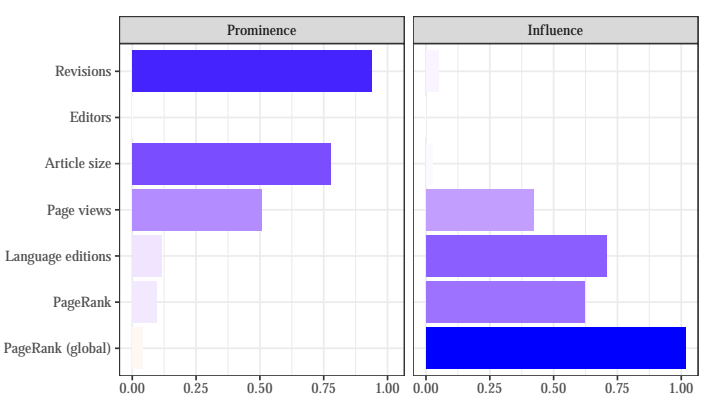

(d) Variable dropped: Page views

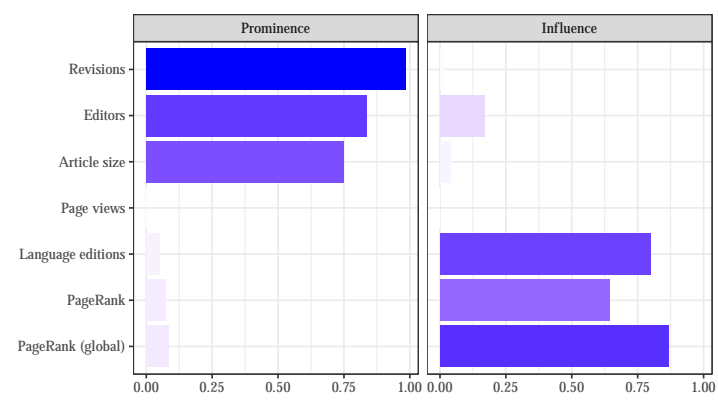

(f) Variable dropped: PageRank

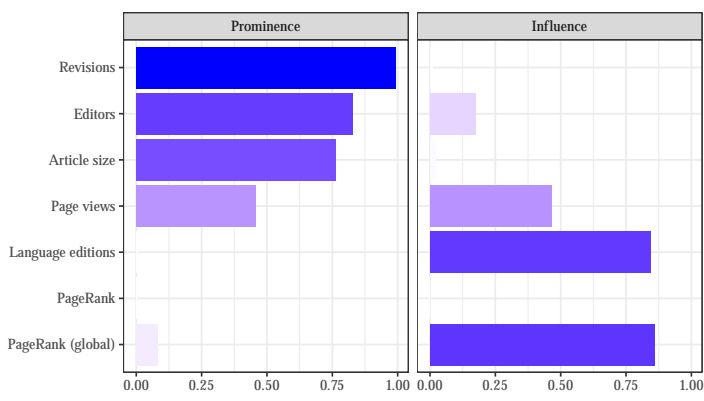

(h) Variable dropped: none

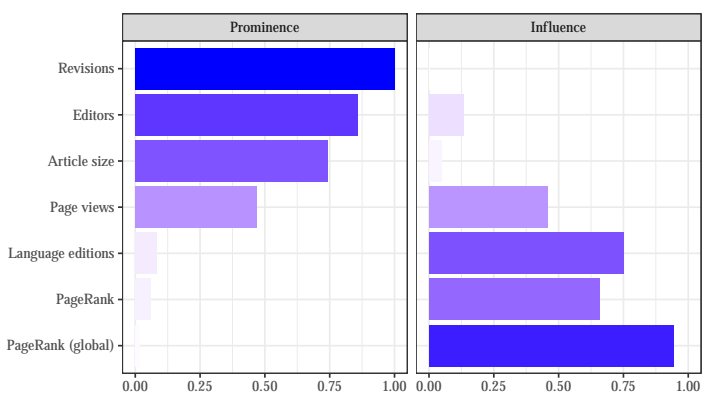




\section{Appendix C Applying PageRank to political elites on Wikipedia}

Technically, the PageRank of a page $p_{i}$ that is part of a universe of $p_{1}, \ldots, p_{N}$ pages, is given by

$$
\operatorname{PageRank}\left(p_{i}\right)=\frac{1-d}{N}+d \sum_{p_{j} \in M\left(p_{i}\right)} \frac{\operatorname{PageRank}\left(p_{j}\right)}{L\left(p_{j}\right)},
$$

where $M\left(p_{i}\right)$ represents the set of pages that link to $p_{i}$ and $L_{p_{j}}$ is the number of outgoing links on page $p_{j}$. In other words, a page's PageRank is higher the more pages refer to it, which consequently contributes more weight. The output represents the likelihood of a random click on a link in the network leading to a particular page. $d$ is then the so-called damping factor-the probability that any user clicking through this network will stop at any step - and is commonly set to 0.85 (Brin and Page, 1998, 4). Therefore, a PageRank of 0.1 implies a 10\% probability that a click on a random link leads to a particular page with that PageRank. In real-world examples, these PageRank values are generally much smaller.

Figure C6 illustrates the logic of the PageRank algorithm. Consider the directed graph as provided in Panel C6a. A is a very prominent node in the network, as many other nodes

Figure C6: Illustration of the PageRank algorithm

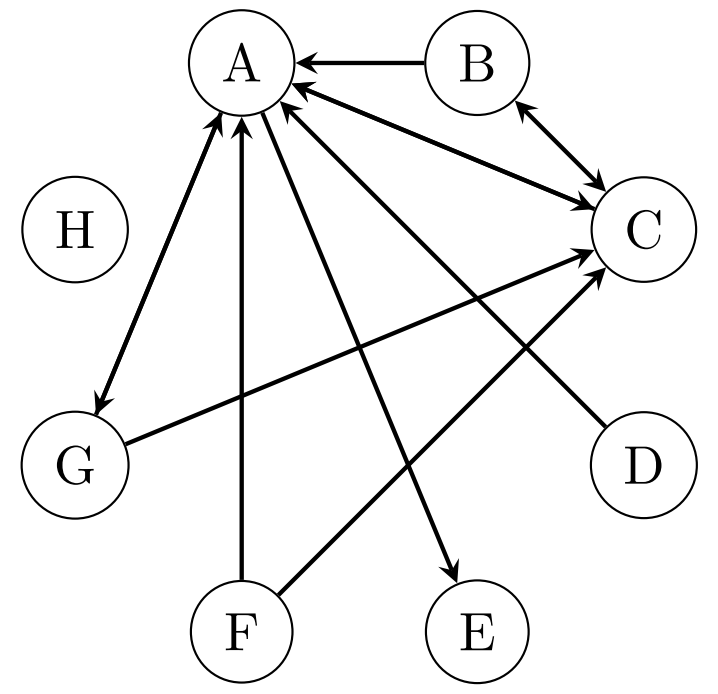

(a) Schematic representation of directed graph

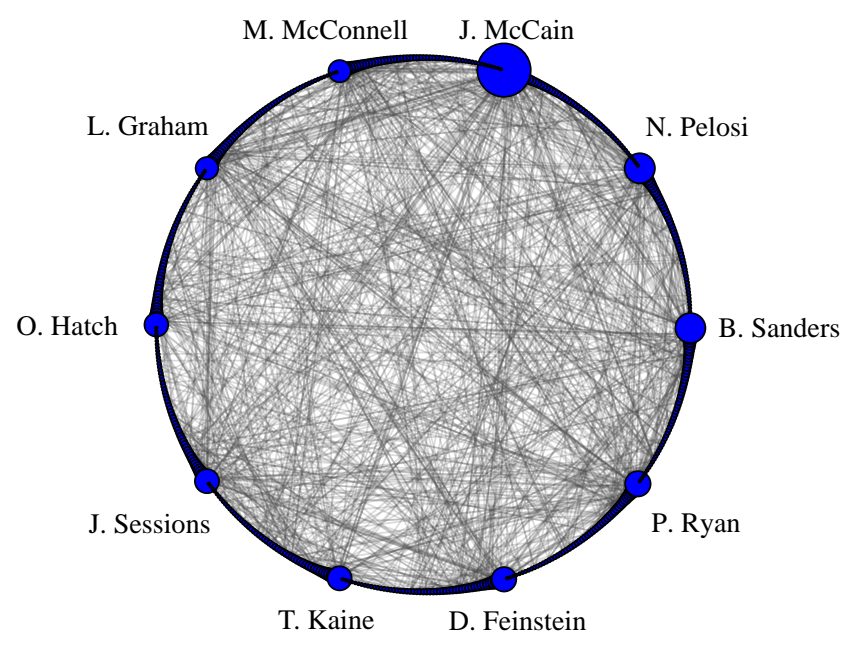

(b) PageRank graph of 115th Congress 
point to it. E has only one incoming link, but the edge comes from A, resulting in a portion of the prominence of A reflecting on $\mathrm{E}$. Node F is connected by two edges, both of which are outgoing. Therefore $\mathrm{F}$ will be described as fairly unimportant. The right-hand panel C6b applies the PageRank on the members of the 115th United States Congress. Larger circles represent higher PageRank values. We see that very few politicians dominate this ranking: Highest scoring is John McCain, who did not hold a formal leadership position at that point but can be considered one of the most important politicians in that legislature, running for President as the Republican nominee in 2008 and holding House and Senate positions between 1982 and 2018. Other high-ranking politicians include House Minority Leader Nancy Pelosi and her Republican counterpart, Paul Ryan, but additionally people with high seniority, such as Dianne Feinstein (Senate member since 1992) or Orrin Hatch (Senate member since 1977).

Finally, note that focusing on incoming instead of outgoing links as a metric of influence makes the measure robust towards self-serving edits, a phenomenon that has been described before (Göbel and Munzert, 2018): In order to boost a politician's prominence, an editor would have to smuggle a link to her article from a relatively more central person or institution, thus, edit a more central article. Irrelevant links (e.g., a link from a rank-and-file member's entry to the President's entry, or the other way round, reporting a one-time encounter during a campaign rally) should therefore not be a major issue. 


\section{Appendix D Amazon MTurk rating}

\section{Sampling of politicians}

Two populations of politicians were considered for the human rating tasks: U.S. presidents $(n=44)$ and members of the 115th Congress $n=535$. In case of the latter, in a trade-off between obtaining a reasonably large sample size, collecting enough ratings per politician, and not burdening the workers with hardly tractable problems (e.g., comparing two generally unknown politicians), the sample was restricted to the most important members of Congress (derived from the Wikipedia-based scores) as well as a random sample of politicians with average influence and prominence scores. The pairwise comparisons were only constructed within instead of across these samples, i.e. workers had to judge pairs of presidents and pairs of members of Congress, but not mixtures of both samples. Pairwise comparisons are a relatively easy-to-solve problem for crowd workers, as it reduces the choice set to two options. To derive a meaningful ranking from pairwise comparisons, multiples of these comparisons have to be ranked.

The Bradley-Terry model, which is used to estimate the latent scores, does not require all possible pairs of individuals from a population in order to derive a full ranking. This proves particularly beneficial, as the number of items (politicians) is rather high and the budget does not allow for gathering data on all possible comparisons, let alone multiple independent runs to allow for checks of inter-rater reliability. (To illustrate: In the case of the 44 presidents alone, this would result in $\frac{n !}{k !(n-k) !}=\left(\begin{array}{l}n \\ k\end{array}\right)=\left(\begin{array}{c}44 \\ 2\end{array}\right)=946$ unique pairs.) On the other hand, a more complete matrix of queried pairs delivers more precise estimates. It is not feasible to complete this for the entire set of politicians, which is why I focus on the arguably more important ones and a random sample of less important legislators. In addition, as most of the raters are likely to be unaware of the less important politicians in the population, it provides little information to let them compare a high-rank with a completely unknown politician (or pairs of unknown politicians). Furthermore, it is more rigorous to compare rankings of politicians with similar levels of importance than it is with vastly different levels of importance when carrying out validity tests. 
Sampling from the set of members of Congress was done as follows: I constructed a variable with theoretical bounds $O$ and 1 from the squared sum of the prominence and influence scored derived from the Bayesian model. To that end, the squared sum was normalized and then the inverse logit was taken. Observations with a value on this variable greater than 0.8 were taken into the sample (43 politicians in total, 34 of which belonged to the Senate). Another 56 politicians were randomly drawn (23 from each chamber) from the subset of observations with values between 0.5 and 0.8 on the prominence-influence variable. This gave a sample of 99 medium- to high-profile members of Congress, 37 from the House and 62 from the senate.

The extracted members of congress are ( $\mathrm{S}=$ Senate, $\mathrm{H}=$ House): Lamar Alexander $(\mathrm{S})$, Tammy Baldwin (S), Richard Blumenthal (S), Cory Booker (S), Bob Brady (H), Sherrod Brown (S), Richard Burr (S), Maria Cantwell (S), Ben Cardin (S), Tom Carper (S), Bob Casey, Jr. (S), Steve Chabot (H), Judy Chu (H), David Cicilline (H), Thad Cochran (S), Steve Cohen (H), Susan Collins (S), John Conyers, Jr. (H), Bob Corker (S), John Cornyn (S), Charlie Crist (H), Peter A. DeFazio (H), Dick Durbin (S), Eliot L. Engel (H), Joni Ernst (S), Dianne Feinstein (S), Deb Fischer (S), Al Franken (S), Kirsten Gillibrand (S), Lindsey Graham (S), Chuck Grassley (S), Alcee L. Hastings (H), Orrin Hatch (S), Martin Heinrich (S), John Hoeven (S), Chris Van Hollen (S), Steny H. Hoyer (H), James Inhofe (S), Johnny Isakson (S), Darrell Issa (H), Sheila Jackson-Lee (H), Ron Johnson (S), Tim Kaine (S), Marcy Kaptur (H), Peter T. King (H), Angus King (S), Amy Klobuchar (S), Raul Labrador (H), Patrick Leahy (S), John Lewis (H), Joe Manchin (S), Ed Markey (S), John McCain (S), Kevin McCarthy (H), Claire McCaskill (S), Mitch McConnell (S), Jim McGovern (H), Bob Menendez (S), Jerry Moran (S), Chris Murphy (S), Patty Murray (S), Jerrold Nadler (H), Bill Nelson (S), Kristi Noem (H), Eleanor Holmes Norton (H), Devin Nunes (H), Rand Paul (S), Erik Paulsen (H), Nancy Pelosi (H), Ted Poe (H), Jared Polis (H), Mike Pompeo (H), Rob Portman (S), Pat Roberts (S), Mike Rounds (S), Marco Rubio (S), Paul Ryan (H), Bernie Sanders (S), Ben Sasse (S), Brian Schatz (S), Adam Schiff (H), Debbie Wasserman Schultz (H), Chuck Schumer (S), Jeff Sessions (S), Richard Shelby (S), Kyrsten Sinema (H), Louise Slaughter (H), Chris Smith (H), Debbie Stabenow (S), John Thune (S), Thom 
Tillis (S), Pat Toomey (S), Niki Tsongas (H), Tom Udall (S), Fred Upton (H), Mark Warner (S), Elizabeth Warren (S), Maxine Waters (H), Ron Wyden (S).

\section{Construction of task pairs}

As the budget did not allow to gather data on all possible comparisons $\left(\left(\begin{array}{c}44 \\ 2\end{array}\right)=946\right.$ unique pairs for the presidents and $\left(\begin{array}{c}99 \\ 2\end{array}\right)=4,851$ unique pairs for the sample of members of Congress), the sample of pairs had to be reduced to a tractable size. I proceeded in 5 steps:

1. Partition the sample into three quantiles of low, mid, and high prominence based on their prominence score.

2. Generate pair-level indicators of prominence, such as high-high, high-low, highmid, mid-low, etc.

3. Assign subjective probability weights on the pair level. High-high combinations got the highest weights, high-low, mid-low and low-low combinations the lowest weights.

4. Sample unique pairs without replacement and using the subjective probability weights. The number of unique pairs to be sampled was determined such that for a fixed number of raters, four raters on average had to rate the same pair.

5. Create task sets of comparisons from unique pairs without replacement for each of the raters.

The steps were applied separately to both groups of politicians, i.e. no presidentCongress member comparisons were created. Ultimately, this procedure guaranteed that (a) more relevant than irrelevant comparisons were sampled, (b) high-profile politicians were disproportionally higher represented, and (c) on average, every unique pair was represented four times in each of the task set. 


\section{Task interface}

Figures D7 to D11 document the interface presented to the MTurk workers. On the Welcome screen (see Figure D7), raters were provided with basic information and instructions to properly work on the task. The tasks were split up in four sub-tasks: ratings which politician is more well-known in the American public (Task 1, see Figure D8), which politician is more liked in the American public (Task 2, see Figure D9), which politician has had more impact in shaping American politics (Task 3, see Figure D10), and a brief survey on sociodemographics, political interest, and affiliation (Task 4, see Figure D11). For each of the rating tasks, the first five comparisons were between U.S. presidents and the remaining 15 comparisons were between members of Congress.

\section{Rater statistics and remuneration}

Table D8 provides an overview of rater and task statistics. Estimating a median completion time of 7 minutes (which turned out to be 8.2 minutes in the sample) and aiming to pay participants an equivalent of at about $\$ 10 / \mathrm{h}$, I paid respondents $\$ 1.25$ per completed task and allowed them to participate up to three times. The workers had to meet the following qualifications: a task approval rate greater than $98 \%$, a minimum number of tasks approved greater than 5,00o, and being located in the United States.

Table D8: Task and agreement statistics on MTurk rating tasks.

\begin{tabular}{|c|c|c|c|c|c|c|c|}
\hline & & Politicians & Pairs & Raters/pair & Agreement & Perfect agreement & Minority votes \\
\hline \multirow{3}{*}{ Presidents } & Well-known & 44 & 126 & 4.56 & 0.88 & 0.60 & 0.11 \\
\hline & Liked & 44 & 126 & 4.55 & 0.85 & 0.54 & 0.11 \\
\hline & Impact & 44 & 128 & 4.55 & 0.80 & 0.36 & 0.14 \\
\hline \multirow{3}{*}{ Members of Congress } & Well-known & 92 & 375 & 4.66 & 0.82 & 0.43 & 0.13 \\
\hline & Liked & 92 & 374 & 4.63 & 0.72 & 0.19 & 0.20 \\
\hline & Impact & 92 & 377 & 4.58 & 0.78 & 0.31 & 0.17 \\
\hline
\end{tabular}

Notes: Politicians = number of unique politicians, Pairs = number of unique pairs, Raters $/$ pair = average number of raters per pair, Agreement = average agreement rate among raters, Perfect agreement $=$ share of pairs with perfect agreement among raters, Minority votes $=$ share of votes that did not go with the majority on each task. 
Figure D7: Rating task on Amazon MTurk: Screenshot of task introduction

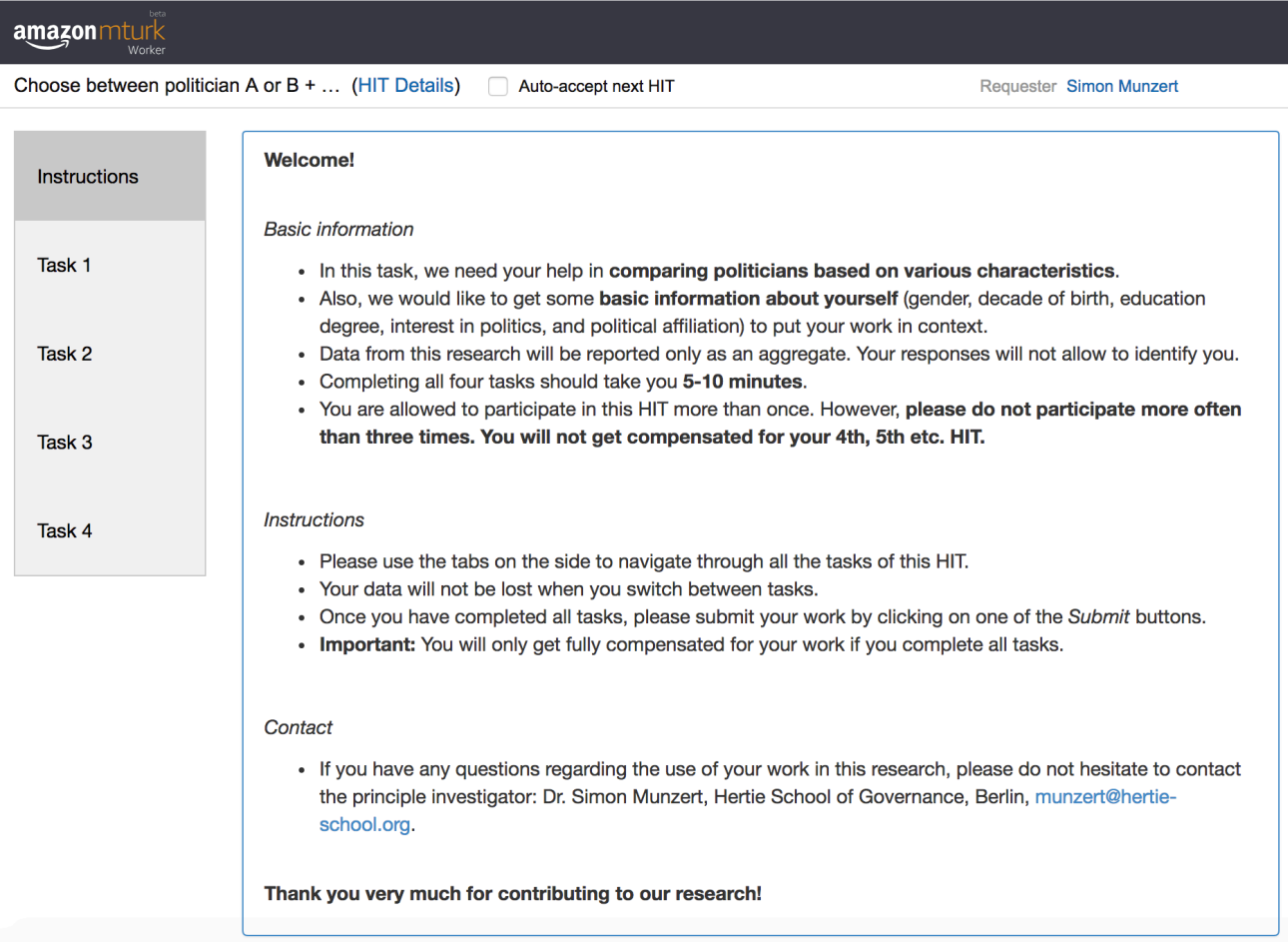

Figure D8: Rating task on Amazon MTurk: Screenshot of rating task 1

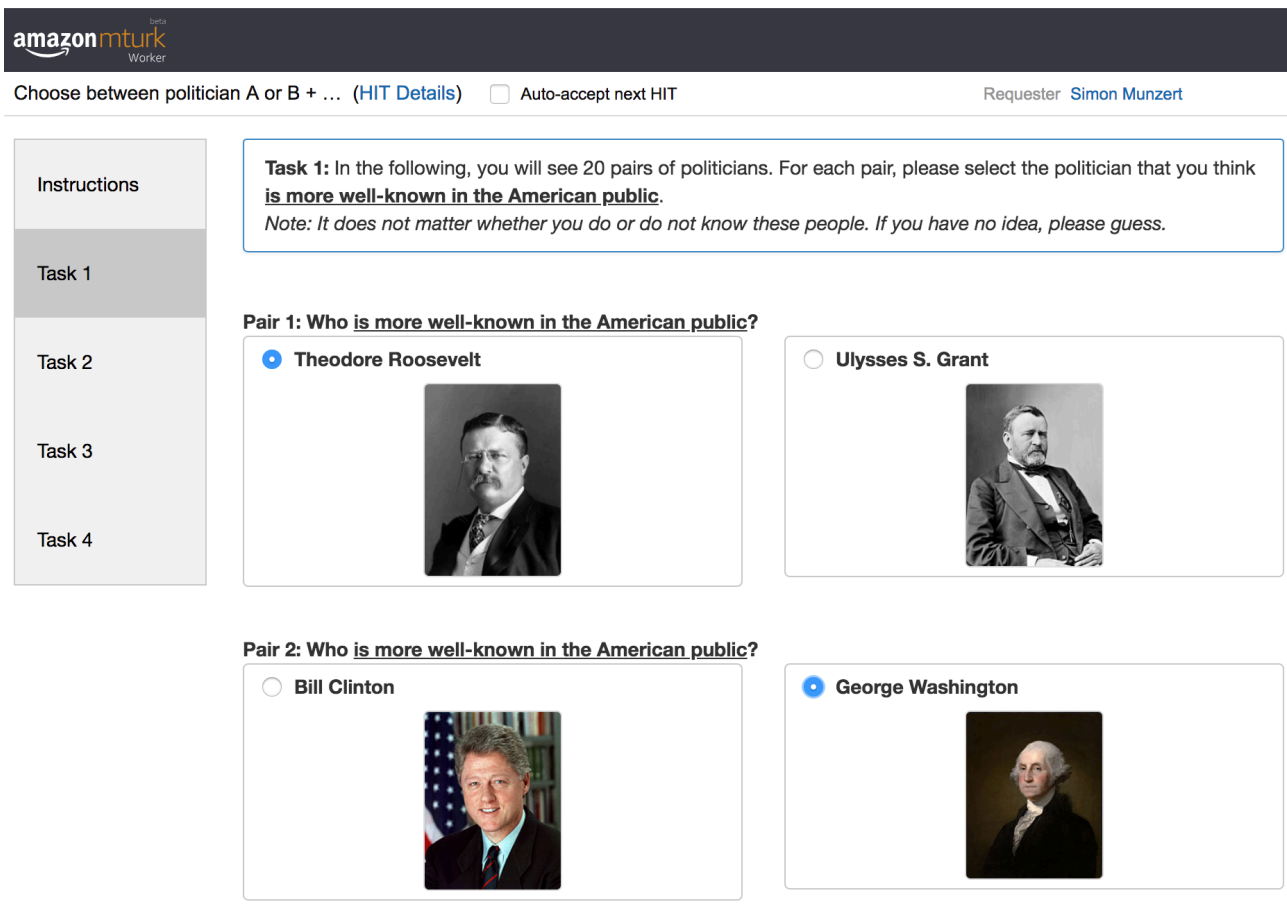


Figure D9: Rating task on Amazon MTurk: Screenshot of rating task 2

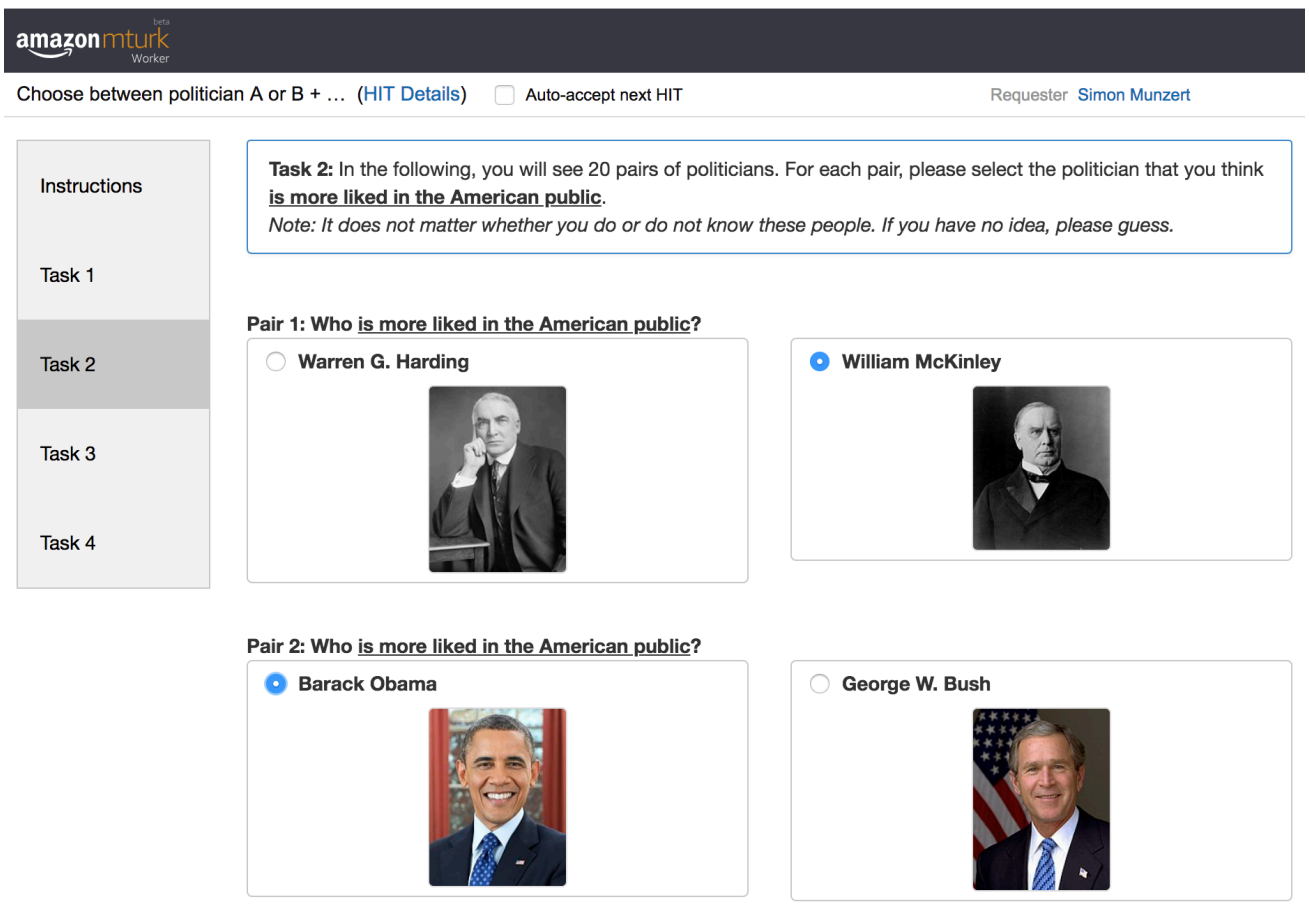

Figure D10: Rating task on Amazon MTurk: Screenshot of rating task 3

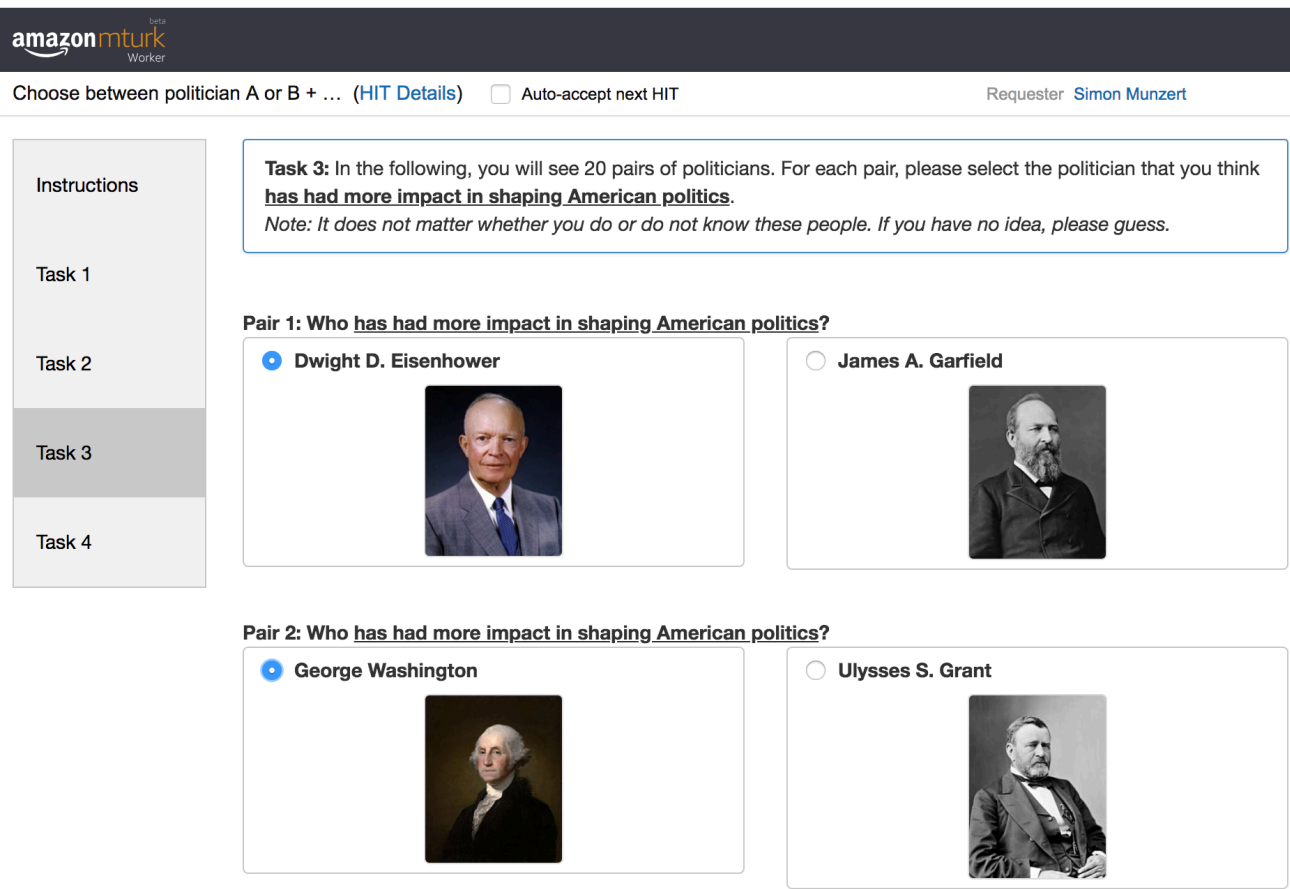




\section{Figure D11: Rating task on Amazon MTurk: Screenshot of survey}

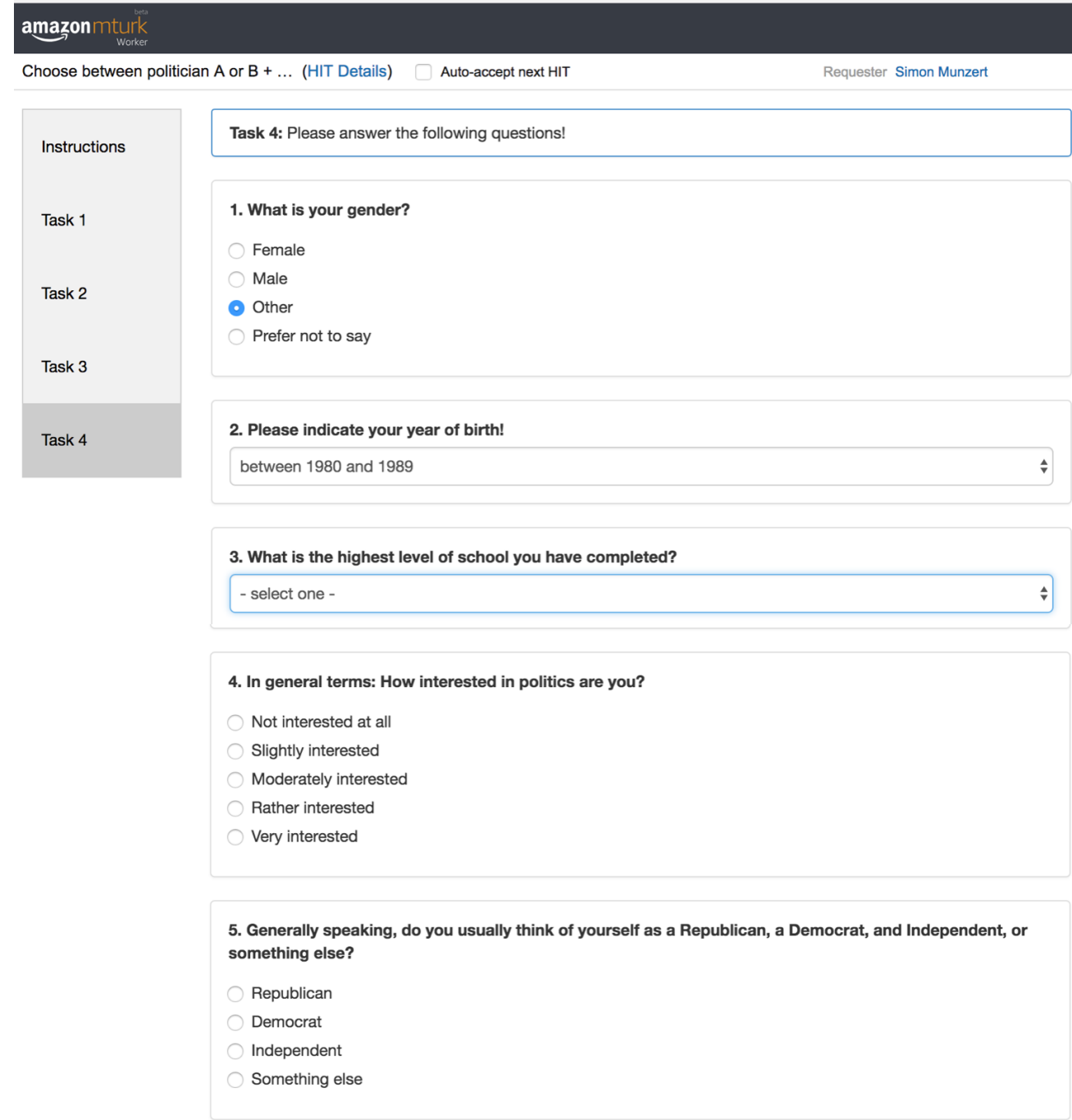




\section{Appendix E Software statement}

The entire analysis was run under OS X 10.13.5 using R version 3.4.1 R Core Team (2017). In the empirical analysis, I made use of the following $\mathrm{R}$ software packages:

BradleyTerryScalable (Kaye and Firth, 2017),

broom (Robinson, 2015),

coda (Plummer et al., 2006),

coefplot (Lander, 2013),

corrplot (Wei and Simko, 2017),

doMC (Analytics and Weston, 2017),

dplyr (Wickham and Francois, 2015),

formattable (Ren and Russell, 2016),

fuzzyjoin (Robinson, 2018),

ggplot2 (Wickham, 2016),

ggrepel (Slowikowski, 2018),

ggridges (Wilke, 2018),

ggthemes (Arnold, 2018),

GPArotation (Bernaards and I.Jennrich, 2005), gtools (Warnes, Bolker and Lumley, 2018),

haven (Wickham, 2016),

igraph (Csardi and Nepusz, 2006),

ISLR (James et al., 2017),

janitor (Firke, 2018),

jsonlite (Ooms, 2014),

legislatoR (Göbel and Munzert, 2017),

lubridate (Grolemund and Wickham, 2011),

magrittr (Bache and Wickham, 2014),
MASS (Venables and Ripley, 2002),

Matrix.utils (Varrichio, 2018),

networkD3 (Allaire et al., 2017),

pageviews (Keyes and Lewis, 2016),

plyr (Wickham, 2011),

pscl (Jackman, 2017),

psych (Revelle, 2018),

purrr (Henry and Wickham, 2018),

R2jags (Su and Yajima, 2015),

readr (Wickham, Hester and Francois, 2017),

reshape2 (Wickham, 2007),

rjags (Plummer, 2016),

rtimes (Chamberlain, 2017),

runjags (Denwood, 2016),

rvest (Wickham, 2015a),

scales (Wickham, 2018),

stargazer (Hlavac, 2015),

stringr (Wickham, 2015b),

tidyr (Wickham and Henry, 2018),

webshot (Chang, 2017), WikipediR (Keyes and Tilbert, 2017),

xtable (Dahl, 2016), and

WikidataR (Keyes et al., 2017). 


\section{References}

Allaire, J.J., Christopher Gandrud, Kenton Russell and CJ Yetman. 2017. networkD3: D3 JavaScript Network Graphs from R. R package version 0.4.

Analytics, Revolution and Steve Weston. 2017. doMC: Foreach Parallel Adaptor for 'parallel'. R package version 1.3.5.

Arnold, Jeffrey B. 2018. ggthemes: Extra Themes, Scales and Geoms for 'ggplot2'. R package version 3.5.0.

Bache, Stefan Milton and Hadley Wickham. 2014. magrittr: A Forward-Pipe Operator for R. R package version 1.5 .

Bernaards, Coen A. and Robert I.Jennrich. 2005. "Gradient Projection Algorithms and Software for Arbitrary Rotation Criteria in Factor Analysis." Educational and Psychological Measurement 65:676-696.

Brin, Sergey and Larry Page. 1998. The Anatomy of a Large-Scale Hypertextual Web Search Engine. In Proceedings of the 7th World-Wide Web Conference. Brisbane, Australia: pp. 1-20.

Cattell, Raymond B. 1966. "The Scree Test for the Number of Factors." Multivariate Behavioral Research 1(2):245-276.

Chamberlain, Scott. 2017. rtimes: Client for New York Times APIs. R package version 0.5.o.

Chang, Winston. 2017. webshot: Take Screenshots of Web Pages. R package version 0.5.o.

Csardi, Gabor and Tamas Nepusz. 2006. “The igraph software package for complex network research.” InterJournal Complex Systems:1695.

Dahl, David B. 2016. xtable: Export Tables to LaTeX or HTML. R package version 1.8-2.

Denwood, Matthew J. 2016. "runjags: An R Package Providing Interface Utilities, Model Templates, Parallel Computing Methods and Additional Distributions for MCMC Models in JAGS." Journal of Statistical Software 71(9):1-25.

Firke, Sam. 2018. janitor: Simple Tools for Examining and Cleaning Dirty Data. R package version 1.o.o.

Göbel, Sascha and Simon Munzert. 2017. "legislatoR: Political, sociodemographic, and Wikipedia-related data on political elites.” https://github.com/saschagobel/legislatoR.

Göbel, Sascha and Simon Munzert. 2018. "Political Advertising on the Wikipedia Marketplace of Information." Social Science Computer Review 36(2):157-175.

Grolemund, Garrett and Hadley Wickham. 2011. "Dates and Times Made Easy with lubridate.” Journal of Statistical Software 40(3):1-25.

Henry, Lionel and Hadley Wickham. 2018. purrr: Functional Programming Tools. R package version 0.2.5.

Hlavac, Marek. 2015. stargazer: Well-Formatted Regression and Summary Statistics Tables. Cambridge, USA: Harvard University. R package version 5.2.

Horn, John L. 1965. "A rationale and test for the number of factors in factor analysis." Psychometrika 30(2):179-185.

Jackman, Simon. 2017. pscl: Classes and Methods for $R$ Developed in the Political Science Computational Laboratory. Sydney, New South Wales, Australia: United States Studies Centre, University of Sydney. R package version 1.5.2. 
James, Gareth, Daniela Witten, Trevor Hastie and Rob Tibshirani. 2017. ISLR: Data for an Introduction to Statistical Learning with Applications in R. R package version 1.2.

Kaye, Ella and David Firth. 2017. BradleyTerryScalable: Fits the Bradley-Terry Model to Potentially Large and Sparse Networks of Comparison Data.

Keyes, Oliver and Brock Tilbert. 2017. WikipediR: A MediaWiki API Wrapper. R package version 1.5.o.

Keyes, Oliver and Jeremiah Lewis. 2016. pageviews: An API Client for Wikimedia Traffic Data. R package version 0.3.0.

Keyes, Oliver, Serena Signorelli, Christian Graul and Mikhail Popov. 2017. WikidataR: API Client Library for 'Wikidata'. R package version 1.4.0.

Lander, Jared P. 2013. coefplot: Plots Coefficients from Fitted Models. R package version 1.2.o.

Ooms, Jeroen. 2014. "The jsonlite Package: A Practical and Consistent Mapping Between JSON Data and R Objects." arXiv:1403.2805 [stat.CO] .

Plummer, Martyn. 2016. rjags: Bayesian Graphical Models using MCMC. R package version 4-6.

Plummer, Martyn, Nicky Best, Kate Cowles and Karen Vines. 2006. “CODA: Convergence Diagnosis and Output Analysis for MCMC.” R News 6(1):7-11.

R Core Team. 2017. R: A Language and Environment for Statistical Computing. Vienna, Austria: R Foundation for Statistical Computing.

Ren, Kun and Kenton Russell. 2016. formattable: Create 'Formattable' Data Structures. R package version 0.2.0.1.

Revelle, William. 2018. psych: Procedures for Psychological, Psychometric, and Personality Research. Evanston, Illinois: Northwestern University. R package version 1.8.4.

Robinson, David. 2015. broom: Convert Statistical Analysis Objects into Tidy Data Frames. R package version 0.3.7.

Robinson, David. 2018. fuzzyjoin: Join Tables Together on Inexact Matching. R package version 0.1.4.

Slowikowski, Kamil. 2018. ggrepel: Automatically Position Non-Overlapping Text Labels with 'ggplot2'. $\mathrm{R}$ package version 0.8.0.

Su, Yu-Sung and Masanao Yajima. 2015. R2jags: Using R to Run 'JAGS'. R package version 0.5-7.

Varrichio, Craig. 2018. Matrix.utils: Data.frame-Like Operations on Sparse and Dense Matrix Objects. R package version 0.9.7.

Venables, W. N. and B. D. Ripley. 2002. Modern Applied Statistics with S. Fourth ed. New York: Springer. ISBN 0-387-95457-0.

Warnes, Gregory R., Ben Bolker and Thomas Lumley. 2018. gtools: Various R Programming Tools. R package version 3.8.1.

Wei, Taiyun and Viliam Simko. 2017. R package "corrplot": Visualization of a Correlation Matrix. (Version $0.84)$.

Wickham, Hadley. 2007. "Reshaping Data with the reshape Package." Journal of Statistical Software 21(12):1-20. 
Wickham, Hadley. 2011. “The Split-Apply-Combine Strategy for Data Analysis.” Journal of Statistical Software 40(1):1-29.

Wickham, Hadley. 2015a. rvest: Easily Harvest (Scrape) Web Pages. R package version 0.3.0.

Wickham, Hadley. 2015b. stringr: Simple, Consistent Wrappers for Common String Operations. R package version 1.0.0.

Wickham, Hadley. 2016. ggplot2: Elegant Graphics for Data Analysis. Springer-Verlag New York.

Wickham, Hadley. 2018. scales: Scale Functions for Visualization. R package version 1.o.o.

Wickham, Hadley, Jim Hester and Romain Francois. 2017. readr: Read Rectangular Text Data. R package version 1.1.1.

Wickham, Hadley and Lionel Henry. 2018. tidyr: Easily Tidy Data with 'spread()'and 'gather()' Functions. $\mathrm{R}$ package version 0.8.1.

Wickham, Hadley and Romain Francois. 2015. dplyr: A Grammar of Data Manipulation. R package version $0.4 \cdot 3$.

Wilke, Claus O. 2018. ggridges: Ridgeline Plots in 'ggplot2'. R package version 0.5.o. 